\title{
Encapsulation of fish oil in nanofibers by emulsion electrospinning: Physical characterization and oxidative stability
}

García Moreno, Pedro Jesús; Boutrup Stephansen, Karen; van derKruijs, Jules; Guadix, Antonio ; Guadix, Emilia M. ; Chronakis, Ioannis S.; Jacobsen, Charlotte

Published in:

Journal of Food Engineering

Link to article, DOI:

10.1016/j.jfoodeng.2016.03.015

Publication date:

2016

Document Version

Peer reviewed version

Link back to DTU Orbit

Citation (APA):

García Moreno, P. J., Boutrup Stephansen, K., van derKruijs, J., Guadix, A., Guadix, E. M., Chronakis, I. S., \& Jacobsen, C. (2016). Encapsulation of fish oil in nanofibers by emulsion electrospinning: Physical characterization and oxidative stability. Journal of Food Engineering, 183, 39-49.

https://doi.org/10.1016/j.jfoodeng.2016.03.015

\section{General rights}

Copyright and moral rights for the publications made accessible in the public portal are retained by the authors and/or other copyright owners and it is a condition of accessing publications that users recognise and abide by the legal requirements associated with these rights.

- Users may download and print one copy of any publication from the public portal for the purpose of private study or research.

- You may not further distribute the material or use it for any profit-making activity or commercial gain

- You may freely distribute the URL identifying the publication in the public portal 


\section{Accepted Manuscript}

Encapsulation of fish oil in nanofibers by emulsion electrospinning: Physical characterization and oxidative stability

Pedro J. García-Moreno, Karen Stephansen, Jules van der Kruijs, Antonio Guadix, Emilia M. Guadix, Ioannis S. Chronakis, Charlotte Jacobsen

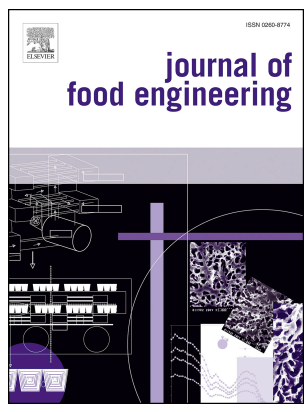

PII:

S0260-8774(16)30091-7

DOI:

10.1016/j.jfoodeng.2016.03.015

Reference: JFOE 8513

To appear in: Journal of Food Engineering

Received Date: 13 January 2016

Revised Date: 20 March 2016

Accepted Date: 25 March 2016

Please cite this article as: García-Moreno, P.J., Stephansen, K., van der Kruijs, J., Guadix, A., Guadix, E.M., Chronakis, I.S., Jacobsen, C., Encapsulation of fish oil in nanofibers by emulsion electrospinning: Physical characterization and oxidative stability, Journal of Food Engineering (2016), doi: 10.1016/ j.jfoodeng.2016.03.015.

This is a PDF file of an unedited manuscript that has been accepted for publication. As a service to our customers we are providing this early version of the manuscript. The manuscript will undergo copyediting, typesetting, and review of the resulting proof before it is published in its final form. Please note that during the production process errors may be discovered which could affect the content, and all legal disclaimers that apply to the journal pertain. 


\section{ENCAPSULATION OF FISH OIL IN NANOFIBERS BY EMULSION}

2 ELECTROSPINNING: PHYSICAL CHARACTERIZATION AND OXIDATIVE

3 STABILITY

4 Pedro J. García-Moreno ${ }^{\mathrm{a}, \mathrm{b} *}$, Karen Stephansen ${ }^{\mathrm{a}}$, Jules van der Kruijs ${ }^{\mathrm{a}, \mathrm{c}}$, Antonio Guadix ${ }^{\mathrm{b}}$, Emilia M.

5 Guadix $^{\mathrm{b}}$, Ioannis S. Chronakis ${ }^{\mathrm{a}}$, Charlotte Jacobsen ${ }^{\mathrm{a}}$

$6 \quad{ }^{a}$ Division of Food Technology, National Food Institute, Technical University of Denmark, Denmark

$7 \quad{ }^{\mathrm{b}}$ Department of Chemical Engineering, University of Granada, Spain

$8{ }^{\mathrm{c}}$ HAS University of Applied Sciences, the Netherlands

\section{ABSTRACT}

The encapsulation of fish oil in poly(vinyl alcohol) (PVA) nanofibers by emulsion electrospinning was

11 investigated. Independently of the emulsifier used, whey protein isolate (WPI) or fish protein hydrolysate (FPH), PVA concentration had a high influence on fiber morphology. Fibers without bead 13 defects were only produced for solutions with $10.5 \%$ (w/w) PVA, which presented sufficient number 14 of polymer chain entanglements. On the other hand, increasing oil load from 1.5 to $3 \%$ (w/w) resulted 15 in fibers with larger diameters containing spindle-like enlargements interspersed. High omega-3 encapsulation efficiency $(92.4 \pm 2.3 \%)$ was obtained for fibers produced from $10.5 \%(\mathrm{w} / \mathrm{w})$ PVA-5\% $(\mathrm{w} / \mathrm{w})$ emulsion blend stabilized with WPI, resulting in an oil load capacity of $11.3 \pm 0.3 \%$. Moreover, the encapsulated oil was randomly distributed as small droplets inside the fibers. However, the electrospun fibers presented a higher content of hydroperoxides and secondary oxidation products (e.g. 1-penten-3-ol, hexanal, octanal and nonanal) compared to emulsified and unprotected fish oil.

21 Keywords: fish oil, nanofibers, emulsion, electrospinning, oxidative stability

\section{INTRODUCTION}

23 Omega-3 polyunsaturated fatty acids (PUFA), particularly eicosapentaenoic (C20:5n-3, EPA) and 24 docosahexaenoic (C22:6n-3, DHA), have numerous beneficial health effects such as prevention of

\footnotetext{
* Corresponding author. Tel: +45 2525 59; Fax: +45 458847 74; E-mail: pejeg@ food.dtu.dk
} 
25

26

27

28

29

cardiovascular disease, improvement of the anti-inflammatory response and development of brain and eye retina in infants (Uauy \& Valenzuela, 2000; Ward \& Singh, 2005). These PUFA need to be ingested through the diet since humans have a low conversion rate of the essential $\alpha$-linolenic fatty acid (ALA) to EPA and DHA (Colussi et al., 2007). As a consequence, the food industry has an increasing interest in developing omega-3 enriched foods. Accordingly, efficient strategies for protecting these highly unsaturated fatty acids against oxidation when incorporated into foods are necessary in order to avoid both the loss of nutritional value and the formation of unpleasant offflavors. For that purpose, omega-3 delivery systems (e.g. fish oil-in-water emulsions and microencapsulated fish oil) are often employed since they can protect the oil against prooxidants in the food system by providing a physical barrier between the omega-3 oil and oxygen or prooxidants (e.g. metal ions) (Jacobsen \& Nielsen, 2007). The employment of emulsified omega-3 oils is more suitable for liquid or semi-liquid foods due to handling/mixing issues. Although a higher oxidative stability was obtained when adding fish oil emulsions to milk, negative results were obtained when adding emulsified fish oil to other food systems such as yoghurt and salad dressings (Let et al., 2007). On the other hand, microencapsulated fish oil, commonly produced by spray-drying, presents in many cases a higher oxidative stability when compared to neat fish oil (Nielsen \& Jacobsen, 2013). Nevertheless, the application of the resulting microcapsules is limited to dry food products (e.g. powdered infant formula) due to their poor solubility (Drusch, 2012). Furthermore, the spray-drying process requires air at high temperature $\left(170-190{ }^{\circ} \mathrm{C}\right)$ which causes initial oxidation of the oil (Serfert et al., 2009). In addition, powdered product is deposited in a large amount on the outlet pipe and chamber wall during spray-drying, which reduces yield (Wan et al., 2011).

Therefore, the development of alternative omega-3 PUFA delivery systems, which are easy to disperse and which lead to improved oxidative stability of omega-3 enriched food products are required. In this sense, electrospinning processing is a straightforward and versatile encapsulation technique suitable for the production of nano-microfibers containing bioactive compounds (Aceituno-Medina et al., 2013; Stephansen et al., 2014). The process uses a high-voltage electro-static field to charge the surface of a polymer solution droplet formed at the end of a capillary tube. Mutual charge repulsion 
causes a force directly opposite to the surface tension which elongates the droplet forming a conical shape known as the Taylor cone. When the electrical forces overcome the surface tension, an electrically charged jet is ejected from the tip of the Taylor cone. On the way to the collector, the jet is stretched out due to several instabilities (e.g. whipping or bending motions) which favor the evaporation of the solvent resulting in dried fibers (Doshi \& Reneker, 1995; Frenot \& Chronakis, 2003). Electrospinning processing presents several advantages such as: i) it does not require heat, thus avoiding deterioration of the active compound, and ii) it results in decreased encapsulates size which allows their incorporation into food systems without affecting the sensory qualities of the product (Li et al., 2013; Weiss et al., 2012).

Recently, lipophilic compounds such as $\beta$-carotene and fish oil have successfully been entrapped into nanofibers produced by electrospinning of zein aqueous-ethanol solutions (Fernandez et al., 2009; Moomand \& Lim, 2014). However, zein, which is a hydrophobic food-approved biopolymer, has a high cost which reduces its use in food applications (Kushwaha \& Kawtikwar, 2013). In this context, emulsion electrospinning is a promising alternative since it allows for the encapsulation of hydrophobic compounds in low-cost hydrophilic polymers, avoiding also the use of organic solvents which are restricted in food systems (Arecchi et al., 2010). A few studies have already been reported on the encapsulation of lipophilic compounds (e.g. mineral oil, hexadecane, limonene, retinyl palmitate and n-butyl acetate) using this technique (Angeles et al., 2008; Arecchi, et al., 2010; Camerlo et al., 2014; Gordon et al., 2015). These authors employed small-sized molecular surfactants such as Pluronic P105 (Angeles, et al., 2008), Tween 20 (Arecchi et al., 2010; Camerlo et al., 2014) and Brij O10, and mixtures of Tween 80 and Span 80 (Gordon et al., 2015) as emulsifiers. Apart from the study of Angeles et al. (2008) which used polyethylene oxide (PEO), the remaining studies employed poly(vinyl) alcohol (PVA) as polymer since it has a higher thermal stability and lower cost than PEO, it is biocompatible, non-toxic, and presents sufficient amounts of chain entanglements which allow for the formation of fibers by electrospinning (Weiss et al., 2012). To the best of the authors' knowledge, no research work on the encapsulation of fish oil in nanofibers obtained by emulsion electrospinning has been previously published. 
Thus, the aim of this work was to study the development of omega-3 delivery systems by emulsion electrospinning using PVA as polymer. Firstly, the effect of polymer concentration, oil load and type of emulsifier on the morphology of the fibers was evaluated. Secondly, the oxidative stability during storage of fish oil encapsulated in selected fibers was studied. Contrarily to previous works, which used low molecular weight surfactants, proteins such as whey protein isolate (WPI) and fish protein hydrolysate (FPH) were assayed as emulsifiers in this study. WPI is normally used in the food industry to stabilize oil-in-water emulsions because of its functional, bioactive and nutritional properties (Adjonu et al., 2014). Recently, FPH has also been reported as a promising alternative emulsifier leading to physical and oxidative stable fish oil-in-water emulsions (García-Moreno et al., 2016; Morales-Medina et al., 2016).

\section{MATERIALS AND METHODS}

\subsection{Materials}

Commercial cod liver oil was kindly provided by Maritex A/S, subsidiary of TINE, BA (Sortland, Norway) and stored at $-40{ }^{\circ} \mathrm{C}$ until use. The fatty acid composition of the fish oil was determined by fatty acid methylation (AOCS, 1998a) followed by separation through GC (AOCS, 1998b). It was as follows (\%,w/w): 9.5\% palmitic acid (C16:0), 8.7\% pamitoleic acid (C16:1n-7), $2.0 \%$ stearic acid (C18:0), 16.3\% oleic acid (C18:1n-9), 4.8\% vaccenic acid (C18:1n-7), 1.8\% linoleic acid (C18:2n-6), 2.6\% $\alpha$-linolenic acid (C18:3n-3), 12.6\% gadoleic acid (C20:1n-11), 9.2\% eicosapentaenoic acid (C20:5n-3), 6.0\% cetoleic acid (C22:1n-11), 11.4\% docosahexaenoic acid (C22:6n-3) and 15.1\% others. The tocopherol content of the fish oil was: $\alpha$-tocopherol, $200 \pm 3 \mu \mathrm{g} / \mathrm{g}$ oil; $\beta$-tocopherol, $5 \pm 1$ $\mu \mathrm{g} / \mathrm{g}$ oil; $\gamma$-tocopherol, $96 \pm 3 \mu \mathrm{g} / \mathrm{g}$ oil and $\delta$-tocopherol, $47 \pm 1 \mu \mathrm{g} / \mathrm{g}$ oil. The peroxide value $(\mathrm{PV})$ of the fish oil used was $0.38 \pm 0.04 \mathrm{meq} / \mathrm{kg}$ oil. Whey protein isolate (WPI), with commercial name Laprodan® DI-9224, was kindly donated by ARLA (ARLA Food Ingredients, Viby, Denmark). Fish protein hydrolysate (FPH) with a degree of hydrolysis of $4 \%$ was produced from sardine muscle using Alcalase 2.4 L (Novozymes, Bagsværd, Denmark) as described by García-Moreno et al. (2016). Three different types of poly(vinyl alcohol) (PVA) were purchased from Sigma-Aldrich (Brøndby, 
Denmark): a) Mowiol ${ }^{\circledR}$ 4-98 (molecular weight = 27,000 Da; degree of hydrolysis = 98-98.8\%), b)

Mowiol ${ }^{\circledR}$ 8-88 (molecular weight $=67,000 \mathrm{Da}$; degree of hydrolysis $\left.=86.7-88.7 \%\right)$, and $\left.\mathrm{c}\right)$ Mowiol ${ }^{\circledR}$

18-88 $($ molecular weight $=130,000 \mathrm{Da}$; degree of hydrolysis $=86.7-88.7 \%)$. PVA partially saponified

(130,000 Da) was kindly provided by Kuraray Europe GmbH.

109

110

111

112

113

114

115

116

117

118

119

120

121

122

123

124

125

126

127

128

129

130

\subsection{Preparation of fish oil-in-water emulsion}

Six different emulsions, stabilized with WPI or FPH and with fish oil content of 5, 7.5 and 10\% (w/w), were produced. Aqueous phases were prepared by dissolving WPI $(1 \%$, w/w) or FPH $(2 \%$, w/w) in distilled water and the $\mathrm{pH}$ was adjusted to $\mathrm{pH} 2$ by addition of $0.1 \mathrm{~N} \mathrm{HCl}$. Acidic $\mathrm{pH}(\mathrm{pH} 2)$ led to the lowest interfacial tension for sardine hydrolysate, which may be related with increased solubility of fish protein at low pH (Morales-Medina et al., 2016). The aqueous solutions were then stirred overnight at $5{ }^{\circ} \mathrm{C}$ to allow complete rehydration of the protein. Primary homogenization was done by adding the fish oil $(5,7.5$ and $10 \%, \mathrm{w} / \mathrm{w})$ slowly to the aqueous phase during mixing at $16,000 \mathrm{rpm}$ (Ystral mixer, Ballrechten-Dottingen, Germany). The fish oil was added during the first minute of mixing, and the total mixing time was $3 \mathrm{~min}$. Secondary homogenization was done on a microfluidizer (M110L Microfluidics, Newton, MA, USA) equipped with a ceramic interaction chamber (CIXC, F20Y, internal dimension $75 \mu \mathrm{m}$ ). Emulsions were homogenized at a pressure of 9,000 psi, running 3 passes. Another emulsion (12\% fish oil-in-water emulsion, w/w) stabilized with WPI was also produced only for measurement of lipid oxidation.

\subsection{Preparation of fish oil-in-water emulsion-PVA solutions for electrospinning}

Preliminary experiments (data not shown) indicated that adding PVA to the aqueous phase before the homogenization process led to the formation of more and larger beads in the fibers. This may be associated to a reduction in the viscosity of the solution as consequence of the homogenization process. Furthermore, adding PVA before the homogenization process also resulted in larger emulsion droplet size, which may decrease the encapsulation efficiency. The influence of the molecular weight of PVA (27, 67 and $130 \mathrm{kDa}$ ) on fiber morphology was also tested in preliminary studies (data not shown). For $10 \%$ (w/w) PVA solutions, a stable Taylor cone could not be obtained for 27 kDa PVA 
131 even when using a low flow rate $(0.01 \mathrm{~mL} / \mathrm{min})$. PVA of 67 and $130 \mathrm{kDa}$ led to stable Taylor cones,

132 however fibers with more and larger beads were produced when using PVA $67 \mathrm{kDa}$ when compared to

133 PVA $130 \mathrm{kDa}$ (data not shown).

134 Therefore, PVA $130 \mathrm{kDa}$ was employed in this study and was added to the aqueous phase after the

135 homogenization process as follows. PVA $(15 \%, \mathrm{w} / \mathrm{w})$ and acetic acid $(1 \%, \mathrm{w} / \mathrm{w})$ were dissolved in

136 distilled water (adjusted at $\mathrm{pH} 2$ by addition of $0.1 \mathrm{~N} \mathrm{HCl}$ ) at $80{ }^{\circ} \mathrm{C}$ under constant stirring for $3 \mathrm{~h}$. The

137 solution was allowed to cool to room temperature under stirring for $2 \mathrm{~h}$ and then overnight without

138 stirring. This PVA polymer solution was blended with fish oil-in-water emulsions in order to obtain

139 electrospinning solutions with PVA concentration of 7.5, 9 and $10.5 \%(\mathrm{w} / \mathrm{w})$. The mixing process was

140 carried out under nitrogen atmosphere by using magnetic stirring for $2 \mathrm{~h}$ at $5{ }^{\circ} \mathrm{C}$ in the dark. A full

141 factorial experimental design with 3 factors (type of emulsifier: WPI and FPH; oil load in emulsions:

142 5, 7.5 and 10\% w/w; and PVA concentration: 7.5, 9 and 10.5\% w/w) and no replicates was carried out.

143 This led to 18 different solutions for electrospinning (Table 1). Samples were used immediately after

144 production for electrospinning processing and subsequently stored at $5{ }^{\circ} \mathrm{C}$ in the dark until further 145 analysis.

\section{$146 \quad 2.4$ Characterization of solutions for electrospinning}

$147 \quad$ 2.4.1 Droplet size

148 Droplet sizes were measured by laser diffraction in a Mastersizer 2000 (Malvern Instruments, Ltd.,

149 Worcestershire, UK). The PVA-emulsion blends were diluted in recirculating water (3000 rpm), until

150 it reached an obscuration of $12 \%$. The refractive indices of sunflower oil (1.469) and water (1.330)

151 were used as particle and dispersant, respectively. Results are given in surface mean diameter $\left(D_{3,2}\right)$.

152 Measurements were made in duplicate at day 1, 3 and 7 after production. Droplet size of the emulsion

153 was also measured immediately after production to evaluate the effect of adding PVA.

\section{$154 \quad 2.4 .2$ Viscosity}

155 The viscosity of electrospinning solutions was measured using a stress controlled rheometer Stresstech

156 (Reologica Instruments AB, Lund, Sweden) equipped with a CC25 standard bob cup system in a 
157

158

159

160

161

162

163

164

165

166

167

168

169

170

171

172

173

174

175

176

177

178

179

180

181

182

temperature vessel. Measurements were done at $20^{\circ} \mathrm{C}$ over a shear stress range from 0.0025 to $20 \mathrm{~Pa}$.

Viscosity was measured twice on each solution at day 1 after production and it was expressed in $\mathrm{mPa} \cdot \mathrm{s}$.

\subsection{Electrospinning process}

The electrospinning solutions were added to a syringe and placed in a syringe pump (New Era Pump Systems, Inc., USA). A 16 G needle (Proto Advantage, Canada) was used. The syringe pump delivered the PVA-emulsion blends with a flow rate of $0.02 \mathrm{ml} / \mathrm{min}$. Using a high voltage power supply (Gamma High Voltage Research, USA), an electric field of $20 \mathrm{kV}$ was applied between the spinneret of the syringe and a $5 \times 5 \mathrm{~cm}$ collector plate made of stainless steel with alumina foil wrapped around it. The distance between the syringe tip and the collector plate was $10 \mathrm{~cm}$. The electrospinning process was conducted at room temperature. From the 18 electrospinning solutions shown in Table 1, electrospun mats were obtained with a fish oil content ranging from 12.0 to $38.4 \%$ $(\mathrm{w} / \mathrm{w})$. Fibers with a final oil content of $12.2 \%(\mathrm{w} / \mathrm{w})$ containing $5 \%(\mathrm{w} / \mathrm{w})$ fish oil-in-water emulsions stabilized with WPI were produced in large quantity for peroxide value and secondary oxidation products determinations. For that purpose, fibers were produced in batches of 5 h. Fibers with $12.2 \%$ (w/w) oil containing 5\% (w/w) fish oil-in-water emulsions stabilized with WPI were also produced for peroxide value determination from: i) a solution containing $13.5 \%(\mathrm{w} / \mathrm{w})$ PVA, and ii) a solution containing $10.5 \%(\mathrm{w} / \mathrm{w})$ PVA and $100 \mathrm{ppm}$ of ethylenediaminetetraacetic acid (EDTA) in the parent emulsion.

\subsection{Characterization of fibers}

Immediately after production, fibers were stored in a desiccator until analyses.

\subsubsection{Morphology}

The morphology of the fibers was investigated using scanning electron microscopy (SEM) (FEI Inspect, Hillsboro, OR, USA). Approximately $0.5 \times 0.5 \mathrm{~cm}$ of the fiber sheet was placed on carbon tape and sputter coated with gold, 10 s, 40 mA utilizing a Cressington 208HR Sputter Coater (Cressington Scientific Instruments, Watford, England). The mean fiber or bead diameters were determined from 
183 the SEM images by image analysis (ImageJ, National Institutes of Health). To this purpose, the

184 diameter of 100 randomly selected fibers and all the beads (if any) presented in the micrograph were

185 measured using the ImageJ software (National Institutes of Health).

186

187

188

189

190

191

192

193

194

195

196

197

198

199

200

201

202

203

204

205

\subsubsection{Lipid distribution}

Before mixing with the PVA solution, selected emulsions were stained with Nile red and fluorescein isothiocyanate to visualize lipids and proteins, respectively. Then, the distribution of the fish oil within the fibers was analyzed with laser scanning confocal microscopy (LSCM) (Zeiss LSM 780, Jena, Germany). The fibers were placed between a coverslip and a glass slide, immersed in immersion oil, and fluorescence after irradiation at $580 \mathrm{~nm}$ or $488 \mathrm{~nm}$ was analyzed. The images were processed using ZEN 2012 lite software (Zeiss, Jena, Germany). Moreover, the droplet size distribution of the emulsion-loaded electrospun fibers after re-dispersion in distilled water was measured as previously described in section 2.4.2. For that purpose, $150 \mathrm{mg}$ of fibers were dissolved in $15 \mathrm{~mL}$ of distilled water at room temperature under magnetic stirring for $30 \mathrm{~min}$. The resulting dispersion was filtered (pore size: $150 \mathrm{~mm}$ ) in order to remove the possible rest of fibers.

\subsubsection{Encapsulation efficiency and loading capacity}

Encapsulation efficiency (EE) and loading capacity (LC) were determined by measuring the nonentrapped fish oil according to Moomand and Lim (2014) with some modifications. Electrospun fibers $(50 \mathrm{mg})$ were submerged in heptane $(10 \mathrm{~mL})$ and gently shaken $(100 \mathrm{rpm})$ for $15 \mathrm{~min}$. The mixture was filtered and the absorbance of the liquid was measured at $250 \mathrm{~nm}$ (UV-1800, Shimadzu, Japan).

The amount of oil present in the liquid was determined from a calibration curve $\left(\mathrm{R}^{2}=0.99\right)$, prepared by dissolving various quantities of fish oil in heptane. The EE and LC values were calculated as:

$$
\begin{aligned}
& E E(\%)=\frac{A-B}{A} * 100 \\
& L C(\%)=\frac{A-B}{C} * 100
\end{aligned}
$$

where $\mathrm{A}$ is the total theoretical amount of fish oil, $\mathrm{B}$ is the free amount of fish oil in the collection solution, and $\mathrm{C}$ is the weight of the fibers. Measurements were carried out in triplicate. 


\subsubsection{Oxidative stability}

209 For lipid oxidation measurements, immediately after production, fibers were stored in $100 \mathrm{~mL}$ brown

210 bottles at $40{ }^{\circ} \mathrm{C}$ in the dark for 14 days. For peroxide value determination each bottle contained 400

$211 \mathrm{mg}$ fibers, and for secondary oxidation products, the bottles contained $150 \mathrm{mg}$ fibers. Unprotected and

212 emulsified fish oil (12\% fish oil-in-water emulsion, w/w; stabilized with WPI) was also analyzed.

213 Samples were taken at day 0, 4, 9 and 14 for analysis.

214

215

216

217

\subsubsection{Determination of peroxide value}

Lipids were extracted from fibers according to the Bligh and Dyer method using a reduced amount of the chloroform/methanol (1:1, w/w) solvent (Bligh \& Dyer, 1959). Two extractions were made from each sample. Peroxide value (PV) was determined on lipid extracts using the colorimetric ferricthiocyanate method at $500 \mathrm{~nm}$ as described by Shantha and Decker (1994).

\subsubsection{Secondary oxidation products - Dynamic headspace GC-MS}

Approximately $40 \mathrm{mg}$ of fibers and $30 \mathrm{mg}$ internal standard (4-methyl-1-pentanol, $30 \mu \mathrm{g} / \mathrm{g}$ water) were weighted out in a $100 \mathrm{~mL}$ purge bottle, to which $5 \mathrm{~mL}$ of distilled water and $1 \mathrm{~mL}$ antifoam (Synperonic $800 \mu \mathrm{L} / \mathrm{L}$ water) were added. The bottle was heated to $45^{\circ} \mathrm{C}$ in a water bath while purging with nitrogen (flow $340 \mathrm{~mL} / \mathrm{min}, 30 \mathrm{~min}$ ). Volatile secondary oxidation products were trapped on Tenax GR tubes. The volatiles were desorbed again by heating $\left(200^{\circ} \mathrm{C}\right)$ in an Automatic Thermal Desorber (ATD-400, Perkin Elmer, Norwalk, CN), cryofocused on a cold trap $\left(-30^{\circ} \mathrm{C}\right)$, released again $\left(220^{\circ} \mathrm{C}\right)$, and led to a gas chromatograph (HP 5890IIA, Hewlett Packard, Palo Alto, CA, USA; Column: DB-1701, 30 m x 0.25 mm x $1.0 \mu \mathrm{m}$; J\&W Scientific, CA, USA). The oven program had an initial temperature of $45^{\circ} \mathrm{C}$ for $5 \mathrm{~min}$, increasing with $1.5^{\circ} \mathrm{C} / \mathrm{min}$ until $55^{\circ} \mathrm{C}$, with $2.5^{\circ} \mathrm{C} / \mathrm{min}$ until $90^{\circ} \mathrm{C}$, and with $12.0^{\circ} \mathrm{C} / \mathrm{min}$ until $220^{\circ} \mathrm{C}$, where the temperature was kept for $4 \mathrm{~min}$. The individual compounds were analyzed by mass-spectrometry (HP 5972 mass-selective detector, Agilent Technologies, USA; electron ionization mode, $70 \mathrm{eV}$; mass to charge ratio scan between 30 and 250). Emulsified fish oil (4g, 12\% oil-in-water emulsion, w/w; stabilized with WPI) and unprotected fish oil ( $4 \mathrm{~g})$ were also analyzed following the same procedure using a nitrogen flow of $150 \mathrm{~mL} / \mathrm{min}(30 \mathrm{~min})$. 
234 In the case of unprotected fish oil, water and antifoam were not added and the bottle was heated at $23560^{\circ} \mathrm{C}$. The individual compounds were identified by both MS-library searches (Wiley $138 \mathrm{~K}$, John 236 Wiley and Sons, Hewlett-Packard) and by authentic external standard. The external standards 237 employed were 2-ethylfuran, 1-penten-3-one, pentanal, 1-penten-3-ol, $(E)$-2-pentenal, hexanal, $(E, E)$ 238 2,4-heptadienal, octanal, nonanal and (E,Z)-2,6-nonadienal (Sigma-Aldrich, Brøndby, Denmark). 239 These compounds were dissolved in $96 \%$ ethanol for fibers and emulsion samples, and rapeseed oil 240 for fish oil samples. Then, the solutions were diluted to concentrations of approximately 1, 5, 10, 25 241 and $100 \mu \mathrm{g} / \mathrm{g}$. Three calibration curves were made by injecting these solutions $(30 \mathrm{mg})$ on $40 \mathrm{mg}$ of 242 fibers dissolved in $5 \mathrm{~mL}$ of water, $4 \mathrm{~g}$ of emulsified fish oil and $4 \mathrm{~g}$ of unprotected fish oil, 243 respectively. Measurements were made in triplicates for each sample.

\section{$244 \quad 2.7$ Statistical analysis}

245 Statgraphics Centurion XV (Statistical Graphics Corp., Rockville, MD, USA) was used for data 246 analysis. Data were expressed as mean \pm standard deviation with two analytical replicates. No 247 experimental replicates were carried out. Firstly, multiple sample comparison analysis was performed 248 to identify significant differences between samples. Secondly, mean values were compared by using 249 the Tukey's test. Differences between means were considered significant at $p<0.05$.

\section{RESULTS AND DISCUSSION}

\subsection{Properties of emulsion-PVA blends}

\section{$252 \quad$ 3.1.1 Droplet size and physical stability}

253 The droplet size distribution, and thus the physical stability, of the electrospinning solutions are 254 important factors to consider since they may affect the lipid distribution and entrapment of fish oil 255 within the nanofibers. Accordingly, the effect of blending PVA solutions and fish oil in-water emulsions on droplet size distribution was evaluated for solutions 1-3 (Table 1). After blending, the 
(2015) which indicated that adding PVA did not modify droplet size distribution of emulsions stabilized with small-sized molecular surfactants such as Tween 20 and Brij O10, respectively.

261 Secondly, the droplet size distribution of the emulsion-PVA blends was studied after production and 262 during storage. Fig. 1a shows the droplet size of the emulsion-PVA $(10.5 \%$, w/w) blends after 1 day of 263 production. Independently of the oil load in the original emulsion, the electrospinning solutions containing emulsions stabilized with WPI presented not significant differences $(p>0.05)$ in their droplet size distribution, with $\mathrm{D}_{3,2}$ values ranging from $130 \pm 1$ to $139 \pm 8 \mathrm{~nm}$. This was also observed for 9 and $7.5 \%$ (w/w) PVA-emulsion blends (data not shown). The droplet sizes of the PVA-emulsion blends were in line with previously reported results for $10 \%(\mathrm{w} / \mathrm{w})$ fish oil-in-water emulsions stabilized with WPI $\left(\mathrm{D}_{3,2}=129 \pm 1 \mathrm{~nm}\right)$ (Horn et al., 2013). For electrospinning solutions containing emulsions stabilized with FPH, significantly $(\mathrm{p}<0.05)$ larger droplet sizes were obtained independently of the oil concentration when compared to solutions containing emulsions stabilized with WPI. Furthermore, the droplet size of these solutions increased significantly $(\mathrm{p}<0.05)$ with the oil load of the 272 original emulsion, with $\mathrm{D}_{3,2}$ values varying from $137 \pm 1$ to $187 \pm 1 \mathrm{~nm}$ for solutions containing 5 and $10 \%$ (w/w) fish oil-in-water emulsions, respectively. This indicates a lower adsorption capacity of FPH at the interface, which only allows the stabilization of larger droplets with a reduced interfacial area. Similar results were found for all PVA concentrations (data not shown).

Contrary to parent emulsions, which slightly destabilized during storage, electrospinning solutions containing emulsions $(5,7.5$ and $10 \%$ oil, w/w) stabilized with WPI did not differ significantly $(\mathrm{p}>0.05)$ in their surface mean diameters after one week of storage (Fig 1b). Similar observations were made for emulsions dispersed in PVA solutions with low concentrations ( 9 and $7.5 \%$, w/w), and it may be attributed to a stabilizing effect of PVA on the emulsions, which reduces flocculation and coalescence by acting as emulsifier (Ajalloueian et al., 2014) and/or by increasing solution viscosity. Similarly, PVA solutions containing emulsions (5 and 7.5\%, w/w) stabilized with FPH were also physically stable during one week (Fig. 1c). However, despite the stabilizing effect of PVA, the PVA- 
the high physical instability of the original emulsion, which is a consequence of the reduced emulsifying capacity of FPH.

287

288

289

290

291

292

293

294

295

296

297

298

299

300

301

302

303

304

305

\subsubsection{Viscosity}

Different factors have been reported to affect fiber formation and morphology; including solution properties (e.g. viscosity, electrical conductivity, surface tension and solvent volatility), environmental conditions (e.g. temperature and humidity), and process parameters (voltage, flow rate and spinning distance) (Chronakis, 2010; Ramakrishna, 2005). Solution viscosity is mainly dependent on the solvent and on polymer molecular weight and concentration (Weiss et al., 2012). It is a measure for the chain entanglements in the solution, for which reason a minimum viscosity is required to stabilize the jet during the process and to produce continuous fibers (Ghorani \& Tucker, 2015). Fig. 1d shows the dynamic viscosity values for the PVA-emulsion blends. All solutions presented Newtonian behavior with viscosity values ranging from 138 to $608 \mathrm{mPa} \cdot \mathrm{s}$. These values are considerably higher compared to the original emulsions $(<5 \mathrm{mPa} \cdot \mathrm{s})$ due to polymer-polymer and polymer-solvent interactions (Arecchi et al., 2010). In this study, the PVA concentration was the main factor affecting the viscosity of the PVA-emulsion blends. The viscosity increased when raising the polymer concentration, however increasing fish oil load also slightly increased the viscosity of PVA-emulsion blends. These findings are in agreement with the results reported by Arecchi et al. (2010) and Camerlo et al. (2014) on PVA solutions containing limonene and n-hexadecane emulsions, respectively. In the same line, Moomand and Lim (2015) also found a rise in the viscosity of zein aqueous-alcohol solutions when increasing fish oil load from 17 to $30 \%$ (w/w). On the other hand, it should be noted that the type of emulsifier employed (WPI or FPH) had a minor influence on viscosity (Fig. 1d).

\subsection{Fibers morphology}

Uniform electrospun fibers with a circular cross-section and void of defects (e.g. beads) were obtained when using $10.5 \%$ (w/w) PVA-emulsion blends independently of the emulsifier employed. Fibers having a similar average diameters were obtained from 10.5\% (w/w) PVA-5\% (w/w) emulsion blends stabilized with WPI or FPH; $172 \pm 44$ and $163 \pm 45 \mathrm{~nm}$ respectively (Fig. 2a and 3a). These results are in 
311 line with previously reported studies of PVA fibers; $171 \pm 61 \mathrm{~nm}$ for $8 \%(\mathrm{w} / \mathrm{w})$ PVA (130 kDa)

312 (Arecchi et al., 2010) and 221 $\pm 34 \mathrm{~nm}$ for 8\% (w/w) PVA (205 kDa) (Gordon et al., 2014). According

313 to Tao and Shivkumar (2007), the average fiber diameter increased with concentration and molecular

314 weight of PVA. Nevertheless, Arecchi et al. (2010) obtained fibers with similar average diameter for

315 the same type of PVA but using lower concentrations. This may be due to the acidic $\mathrm{pH}$ used in this

316 study ( $\mathrm{pH}$ 2) which led to a decrease in solution viscosity as consequence of the disentanglement of

317 polymer chains (Rwei \& Huang, 2009).

318 Next, the effect of oil load on fiber morphology for the $10.5 \%$ (w/w) PVA-emulsion blends was

319 investigated. For solutions stabilized with WPI, increasing the oil load from 1.5 to $3 \%$ (w/w) did not

320 affect fiber formation (Fig. 2). However, fibers obtained from solutions containing a higher oil 321 concentration had larger and more polydispersed diameters, ranging from $172 \pm 44$ to $252 \pm 68 \mathrm{~nm}$ (Fig.

322 2). Similar results were obtained by Gordon et al. (2014) for PVA fibers containing retinyl palmitate

323 in isohexadecane (oil phase), with fiber diameters of $246 \pm 71$ and $268 \pm 80 \mathrm{~nm}$ for 5.8 and $15 \%$ (w/w)

324 oil phase, respectively. It should also be noted that fibers produced from solutions with an oil load 325 higher than $1.5 \%(\mathrm{w} / \mathrm{w})$, showed spindle-like enlargements interspersed along the fibers (Fig. 2b-c).

326 These morphological changes are different from the bead defects observed by Arecchi et al. (2010)

327 when increasing n-hexadecane content in the PVA-emulsion blend from 0.5 to 1 and $1.5 \%$ (w/w). It 328 may be explained by the higher PVA concentration employed in this study $(10.5 \%$, w/w), which leads 329 to a higher elongation viscosity and reduced surface tension (Rwei \& Huang, 2009). There was no 330 difference between using WPI or FPH as emulsifier in the $10.5 \%$ (w/w) PVA-emulsion blends (data 331 not shown).

332 Independently of the emulsifier employed, the PVA concentration had a major impact on fiber 333 morphology. SEM micrographs of electrospun mats obtained from PVA-5\% (w/w) emulsion blends 334 stabilized with FPH are depicted in Fig. 3, which shows that decreasing PVA concentration from 10.5 335 to $9 \%(\mathrm{w} / \mathrm{w})$ led to the formation of elongated spindle-like beads with an average diameter of $295 \pm 42$ $336 \mathrm{~nm}$ (Fig. 3b). For 7.5\% (w/w) PVA, beads-on-string morphology was observed, with the beads being 
more spherical and with an increased average diameter of $784 \pm 422 \mathrm{~nm}$ (Fig. 3c). Reducing the

\section{8}

339

340

341

342

343

polymer concentration led to fewer chain entanglements, which decreased the viscoelasticity of the jet, thus causing formation of beads since the Rayleigh instability could not be completed avoided (Chang et al., 1999). Although it was expected that increasing the fish oil load $(1.5-2.5 \%, \mathrm{w} / \mathrm{w})$ would increase the average fiber diameter, the mean diameter of the fibers decreased from $163 \pm 45$ to $120 \pm 39$ and $120 \pm 59 \mathrm{~nm}$ for fibers obtained from solutions containing 10.5, 9 and 7.5 PVA\% (w/w), respectively (Fig. 3). Even though it is well known that decreasing PVA concentration leads to a decreased fiber diameter (Koski et al., 2004; Rwei \& Huang, 2009), this decrease may be also attributable to the concentration of flocculated or coalesced droplets of fish oil in the spindle-like or bead structures. A similar finding was reported by Arecchi et al. (2010) when increasing n-hexadecane load in $8 \%(w / w)$ PVA fibers.

\subsection{Characterization of selected fibers}

Fibers made from the $10.5 \%(\mathrm{w} / \mathrm{w})$ PVA-emulsion blend and loaded with $1.5 \%(\mathrm{w} / \mathrm{w})$ fish oil stabilized with WPI (Exp. 1 in Table 1) were selected for further characterization. This solution was chosen since: i) $10.5 \%$ (w/w) PVA was required to obtain uniform fibers without defects, and ii) it presented the lowest droplet size and it was physically stable during storage, which may benefit the entrapment of fish oil inside the fibers.

\subsubsection{Lipid encapsulation and distribution}

Electrohydrodynamic processing offers the possibility to obtain nano-microstructures loaded with large amounts of active compounds. High EE is of outermost significance when working with bioactive compounds prone to oxidation (e.g. fish oil), since it can minimize the exposure of free bioactive compounds to oxygen (Torres-Giner et al., 2010). For the selected PVA-emulsion blend, the initial emulsion droplet size $\left(D_{3,2}=130 \pm 1 \mathrm{~nm}\right.$, Fig. 1a) and the average fiber diameter $(172 \pm 44 \mathrm{~nm}$, Fig. 2a) indicated that most of the fish oil droplets might be entrapped within the PVA fiber. Indeed, this was confirmed by a high EE $(92.4 \pm 2.3 \%)$. This value is within the range of the results reported by

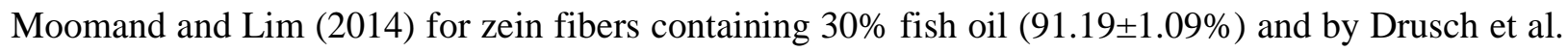


(2012) for fish oil microencapsulates produced with casein hydrolysates using spray-drying (92.4\%).

364 Taking into account that the theoretical fish oil content in the fibers was $12.2 \%(w / w)$, the trapping 365 efficiency achieved led to a LC of $11.3 \pm 0.3 \%$.

366 Another important factor affecting the fish oil oxidative stability is its distribution within the fibers 367 (Moomand \& Lim, 2014). Fig. 4a shows the confocal image of the fibers. Both small and larger green 368 ellipses, marking the protein, were randomly dispersed along the fibers. The small green ellipses could 369 be due to WPI covering the fish oil droplets, whereas the larger green ellipses may mark free WPI that was not adsorbed at the interface in the parent emulsion. The change from spherical to elliptical shape of the droplets was caused by a stretching in the axial direction during the electrospinning process (Gordon et al., 2015). Fish oil (marked in red) was also dispersed along the fibers. However, from the confocal image it was difficult to determine if the fish oil was dispersed as droplets or in a continuous core. To further evaluate the distribution of the oil inside the fibers, the oil-loaded fibers were redispersed in distilled water. Fig. $4 \mathrm{~b}$ depicts the droplet size distribution of the re-dispersed fibers and of the electrospinning solution, which were both almost identical to the parent emulsion, indicating that most of the fish oil was distributed as droplets (with similar size as in the initial emulsion) inside the fibers. This is in accordance with the results of Gordon et al. (2015) on fibers containing retinyl pamitate, and it is also in agreement with the study of Angeles et al. (2008) which reported that the final particle size incorporate into the fibers was highly influenced by the initial emulsion droplet size. However, Fig. 4b also shows a small peak around $100 \mu \mathrm{m}$ for the re-dispersded fibers. It may be the result of agglomeration of some large droplets in the core of the fibers forming a "core-sheath" 383 structure, favored by the evaporation and jet stretching process during electrospinning (Xu et al., 2008; 384 Yarin, 2011).

\subsubsection{Oxidative stability}

Hydroperoxides, which are also known as primary oxidation products, are formed in the early phase of lipid oxidation. Although hydroperoxides are tasteless, they decompose in the presence of heat or 
responsible for the off-flavours (Jacobsen et al., 2013). Table 2 shows that the PV during storage of the fibers was significantly higher $(\mathrm{p}<0.05)$ when compared to the values found for the unprotected and emulsified fish oil. Contrary to emulsified fish oil, a lag phase was not observed for the unprotected fish oil and fibers since PV increased rapidly between days 0 and 4 (especially for fibers). Considering secondary oxidation products, unprotected fish oil showed a high increase in the concentration of volatiles derived from omega-3 PUFA oxidation such as 1-penten-3-ol and (E,E)-2,4heptadienal (Fig. 5a). The presence of these volatiles was also significant in the emulsified fish oil but to a lower extent compared to unprotected fish oil. On the other hand, emulsified fish oil presented a higher increase in the concentration during storage of 2-ethylfuran, another volatile derived from oxidation of omega-3 fatty acids (Fig. 5b). Nevertheless, and as observed for PV, the nanofibers presented the highest increase in the concentration of volatiles during storage. Particularly important was the formation of 1-penten-3-ol and other volatiles such as hexanal and nonanal which were derived from omega-6 and omega-9 fatty acids, respectively (Fig. 5c).

Unexpectedly, these results revealed the inability of the fibers to protect the encapsulated fish oil against oxidation, which was more oxidized than the unprotected counterparts. Even immediately after production, the fibers presented a PV of 54.6 \pm 9.3 meq $\mathrm{O}_{2} / \mathrm{kg}$ oil (Table 2). Therefore, several strategies were carried out in an attempt to enhance the resistance to oxidation of the electrospun nanofibers. First, the electrospinning process was carried out under partial nitrogen atmosphere by using a home-made chamber in order to avoid oxidation of the unentrapped oil during production of the electrospun mats. However, the nanofibers obtained under this partial inert atmosphere only showed a slightly reduced PV (Table 2). Next, the concentration of PVA in the electrospinning solution was increased to $13.5 \%(\mathrm{w} / \mathrm{w})$ aiming at increasing the fiber diameter, and thus improving the entrapment of fish oil. Moomand and Lim (2014) reported that zein nanofibers loaded with fish oil were more oxidatively stable when increasing encapsulation efficiency from $91.19 \pm 1.09$ to 95.88 $\pm 0.23 \%$. Surprisingly, PV at day 0 for fibers produced under nitrogen from a $13.5 \%$ (w/w) PVAemulsion blend was significantly higher $(\mathrm{p}<0.05)$ than for fibers obtained from a $10.5 \%(\mathrm{w} / \mathrm{w})$ PVA- 
properties, was added to the emulsion before blending with the PVA solution. The PV at day 0 for the

417 obtained fibers was not significantly improved (43.9 \pm 7.8 meq $\mathrm{O}_{2} / \mathrm{kg}$ oil). Moreover, PV during storage

418 of the $10.5 \%(w / w)$ PVA-emulsion blend containing $1.5 \%(w / w)$ fish oil and EDTA was considerably

419 higher when compared to emulsified fish oil (Table 2). This finding may denote a negative influence

420 of PVA as carrier matrix on the oxidative stability of encapsulated fish oil. Indeed, the prooxidant

421 effect of PVA was confirmed by the results obtained for a PVA-emulsion blend when using PVA from

422 a different producer (Kuraray Europe GmbH). Table 2 shows that PV of the PVA (Kuraray)-emulsion

423 blend was significantly $(\mathrm{p}<0.05)$ higher at days 9 and 14 when compared to emulsified fish oil. PV of

424 PVA (Kuraray)-emulsion blend was also higher than PVA (Sigma)-emulsion blend at days 9 and 14,

425 probably due to the chelating effect of EDTA added to the latter solution. PVA which is produced in

426 metal equipment has been reported to contain trace quantities of metals (e.g. Ca, Fe, Al) (Zhu, Gao,

$427 \mathrm{Xu}, \& \mathrm{Shi}, 2008)$. It is well known that metal-catalyzed decomposition of lipid peroxides not only

428 generates free radicals, which initiate further oxidation reactions, but also leads to the formation of

429 secondary volatile oxidation products (Frankel, 2005). In this sense, the interaction of PVA metal

430 impurities with existing peroxides present in the de-emulsified fish oil forming the "core-sheath"

431 structure may be an important driving force for lipid oxidation in the nanofibers. Contrarily to these

432 results, Moomand and Lim (2014) and Torres-Giner et al. (2010) encapsulated fish oil in oxidatively

433 stable zein nanofibers and nanocapsules, respectively. In the same line, de Freitas Zômpero et al.

434 (2015) reported that zein is more adequate than PVA to encapsulate $\beta$-carotene by electrospinning

435 since it led to higher protection of this bioactive upon exposure to ultraviolet light. These differences

436 may be explained by the antioxidant properties of zein which are due to its content in carotenoids (e.g.

$437 \quad \beta$-carotene, zeaxanthin and lutein) and sulphur amino acids exhibiting radical scavenging properties

438 (Moomand \& Lim, 2014). Nevertheless, the current high-cost manufacturing methods of zein make it

439 an uneconomical material for food applications (Kushwaha \& Kawtikwar, 2013).

440 It should be also mentioned that the process conditions employed could have also had a negative effect 441 on the oxidative stability of the fibers. In this sense, the long duration of the production batches 
442 together with the no total inert atmosphere used may have favored oxidation of unentrapped fish oil

443 during fibers production.

\section{4. CONCLUSIONS}

445 Nanofibers loaded with fish oil can be successfully produced by emulsion electrospinning using PVA

446 as polymer and WPI or FPH as emulsifiers. WPI exhibited a higher emulsifying property than FPH, 447 and led to more physically stable PVA-emulsion blends with smaller droplet size. A PVA 448 concentration of $10.5 \%(\mathrm{w} / \mathrm{w})$ allowed sufficient chain polymer entanglements required in order to 449 avoid the formation of elongated spindle-like beads or beads-on-string morphologies. Increasing oil 450 load of the PVA-emulsion blends only had a small influence on the formation of fiber defects, apart 451 from the appearance of spindle-like enlargements interspersed along the fibers. Although most of the 452 fish oil was encapsulated inside the fibers as small droplets, the fibers presented a poor oxidative 453 stability. This may be related to the presence of traces of metals (e.g. Fe) in the PVA used, which 454 catalyzed lipid oxidation. Thus, further research on the employment of alternative biopolymers, having 455 a lower price than zein, is required to obtain oxidatively stable fish oil encapsulates by emulsion 456 electrospinning. In addition, an increase in the production rate, which will imply shorter production 457 batches, and the employment of a total inert atmosphere should be also considered in futures studies to 458 reduce oxidation of unentrapped fish oil during fibers production.

\section{ACKNOWLEDGEMENTS}

460 This work was supported by the European Commission (ELECTRONANOMEGA project, Grant 461 Agreement 654818). P.J. García-Moreno also acknowledges a mobility fellowship from the Spanish 462 Ministry of Education, Culture and Sport under the programme "José Castillejo". K. Stephansen and 463 I.S. Chronakis acknowledge the Danish Strategic Research Council (FENAMI project, DSF-10464 93456). The authors would also like to acknowledge the Core Facility for Integrated Microscopy at 465 Faculty of Health and Medical Sciences, University of Copenhagen (Denmark). 
466

467

468

469

470

471

472

473

474

475

476

477

478

479

480

481

482

483

484

485

486

487

488

489

490

\section{REFERENCES}

Aceituno-Medina, M., Mendoza, S., Lagaron, J. M., \& López-Rubio, A. (2013). Development and characterization of food-grade electrospun fibers from amaranth protein and pullulan blends. Food Research International, 54(1), 667-674.

Adjonu, R., Doran, G., Torley, P., \& Agboola, S. (2014). Whey protein peptides as components of nanoemulsions: A review of emulsifying and biological functionalities. Journal of Food Engineering, $122(1), 15-27$.

Ajalloueian, F., Tavanai, H., Hilborn, J., Donzel-Gargand, O., Leifer, K., Wickham, A., \& Arpanaei, A. (2014). Emulsion electrospinning as an approach to fabricate PLGA/chitosan nanofibers for biomedical applications. BioMed Research International, Article ID 475280.

Angeles, M., Cheng, H., \& Velankar, S. S. (2008). Emulsion electrospinning: Composite fibers from drop breakup during electrospinning. Polymers for Advanced Technologies, 19(7), 728-733.

AOCS (1998a). AOCS Official Method Ce 2-66. Preparation of Methyl Esters of Long Chain Fatty Acids. AOCS: Champaign, IL.

AOCS (1998b). AOCS Official Method Ce 1b-89. Fatty Acid Composition by GLC, Marine Oils. AOCS: Champaign, IL.

Arecchi, A., Mannino, S., \& Weiss, J. (2010). Electrospinning of poly(vinyl alcohol) nanofibers loaded with hexadecane nanodroplets. Journal of Food Science, 75(6), N80-N88.

Bligh, E. G., \& Dyer, W. J. (1959). A rapid method for total lipid extraction and purification. Canadian Journal of Biochemistry and Physiology, 37(8), 911-917.

Camerlo, A., Bühlmann-Popa, A., Vebert-Nardin, C., Rossi, R. M., \& Fortunato, G. (2014). Environmentally controlled emulsion electrospinning for the encapsulation of temperature-sensitive compounds. Journal of Materials Science, 49(23), 8154-8162.

Chang, H., Demekhin, E. A., \& Kalaidin, E. (1999). Iterated stretching of viscoelastic jets. Physics of Fluids, 11(7), 1717-1737. 
491 Chronakis, I. S. (2010). Nano-microfibers by Electrospinning Technology: Processing, Properties and 492 Applications. In Y. Quin (Ed.), Micromanufacturing Engineering and Technology (pp. 264-286). 493 Elsevier: Oxford.

494 Colussi, G. L., Catena, C., Baroselli, S., Nadalini, E., Lapenna, R., Chiuch, A., \& Sechi, L. A. (2007). 495 Omega-3 fatty acids: From biochemistry to their clinical use in the prevention of cardiovascular 496 disease. Recent Patents on Cardiovascular Drug Discovery, 2(1), 13-21.

497 de Freitas Zômpero, R. H., López-Rubio, A., de Pinho, S. C., Lagaron, J. M., \& de la Torre, L. G. 498 (2015). Hybrid encapsulation structures based on $\beta$-carotene-loaded nanoliposomes within electrospun 499 fibers. Colloids and Surfaces B: Biointerfaces, 134(1), 475-482

500 Doshi, J., \& Reneker, D. H. (1995). Electrospinning process and applications of electrospun fibers. $501 \quad$ Journal of Electrostatics, 35(2-3), 151-160.

502 Drusch, S. (2012). An industry perspective on the advantages and disadvantages of different fish oil 503 delivery systems. In N. Garti, \& D.J. McClements (Eds.), Encapsulation Technologies and Delivery 504 Systems for Food Ingredients and Nutraceuticals (pp 488-504). Woodhead Publishing Ltd: 505 Cambridge

506 Drusch, S., Serfert, Y., Berger, A., Shaikh, M. Q., Rätzke, K., Zaporojtchenko, V., \& Schwarz, K. 507 (2012). New insights into the microencapsulation properties of sodium caseinate and hydrolyzed 508 casein. Food Hydrocolloids, 27(2), 332-338.

509 Fernandez, A., Torres-Giner, S., \& Lagaron, J. M. (2009). Novel route to stabilization of bioactive 510 antioxidants by encapsulation in electrospun fibers of zein prolamine. Food Hydrocolloids, 23(5), $511 \quad 1427-1432$.

512 Frankel, E. N. (2005) Lipid Oxidation. The Oily Press: Dundee.

513 Frenot, A., \& Chronakis, I. S. (2003). Polymer nanofibers assembled by electrospinning. Current 514 Opinion in Colloid \& Interface Science, 8(1-2), 64-75. 
515 García-Moreno, P.J., Guadix, A., Guadix, E.M., Jacobsen, C. (2016). Physical and oxidative stability 516 of fish oil-in-water emulsions stabilized with fish protein hydrolysates. Food Chemistry, 203(1), 124517135.

518 Ghorani, B., \& Tucker, N. (2015). Fundamentals of electrospinning as a novel delivery vehicle for 519 bioactive compounds in food nanotechnology. Food Hydrocolloids, 51(1), 227-240.

520 Gordon, V., Marom, G., \& Magdassi, S. (2015). Formation of hydrophilic nanofibers from 521 nanoemulsions through electrospinning. International Journal of Pharmaceutics, 478(1), 172-179.

522 Horn, A. F., Wulff, T., Nielsen, N. S., \& Jacobsen, C. (2013). Effect of $\alpha$-lactalbumin and $\beta$ 523 lactoglobulin on the oxidative stability of $10 \%$ fish oil-in-water emulsions depends on pH. Food 524 Chemistry, 141(1), 574-581.

525 Jacobsen, C., \& Nielsen, N. S. (2007). Optimization of oxidative stability of omega-3 enriched foods. 526 In H. Breivik (Ed.), Long-chain omega-3 specialty oils (pp 197-217). The Oily Press Ltd: Bridgwater.

527 Jacobsen, C., Sørensen, A. D. M., \& Nielsen, N. S. (2013). Stabilization of omega-3 oils and enriched 528 foods using antioxidants. In C. Jacobsen, N.S. Nielsen, A.F. Horn, \& A.D.M. Sørensen (Eds.), Food 529 Enrichment with Omega-3 Fatty Acids (pp 130-149). Woodhead Publishing Ltd: Cambridge.

Koski, A., Yim, K., \& Shivkumar, S. (2004). Effect of molecular weight on fibrous PVA produced by electrospinning. Materials Letters, 58(3-4), 493-497.

Kushwaha, A. K., \& Kawtikwar, P. S. (2013). Zein as a natural film forming agent: A review. 533 International Journal of Pharmacy and Technology, 5(2), 2578-2593.

Li, X., Kanjwal, M. A., Lin, L., Fu, J., \& Chronakis, I. S. (2013). Electrospun polyvinyl-alcohol nanofibers as oral fast-dissolving delivery system of caffeine and riboflavin. Colloids and Surfaces B: Biointerfaces, 103(1), 182-188. enriched with neat fish oil or preemulsified fish oil. Journal of Agriculture and Food Chemistry, 
540 Morales-Medina, R., Tamm, F., Guadix, A., Guadix, E. M., \& Drusch, S. (2016). Functional and

541 antioxidant properties of hydrolysates of sardine (S. pilchardus) and horse mackerel ( $T$.

542 mediterraneus) for the microencapsulation of fish oil by spray-drying. Food Chemistry, 194(1), 1208-

5431216

544 Moomand, K., \& Lim, L. (2014). Oxidative stability of encapsulated fish oil in electrospun zein fibres.

545 Food Research International, 62(1), 523-532.

546 Moomand, K., \& Lim, L. (2015). Effects of solvent and n-3 rich fish oil on physicochemical 547 properties of electrospun zein fibres. Food Hydrocolloids, 46(1), 191-200.

548 Nielsen, N. S., Jacobsen, C. (2013) Retardation of lipid oxidation in fish oil enriched fish paté 549 Combination effects. Journal of Food Biochemistry, 37(1), 88-97.

550 Ramakrishna, S. (2005). An Introduction to Electrospinning and Nanofibers. World Scientific: 551 Singapore.

552 Rwei, S., \& Huang, C. (2012). Electrospinning PVA solution-rheology and morphology analyses. 553 Fibers and Polymers, 13(1), 44-50.

554 Serfert, Y., Drusch, S., \& Schwarz, K. (2009). Chemical stabilisation of oils rich in long-chain 555 polyunsaturated fatty acids during homogenisation, microencapsulation and storage. Food Chemistry, 556 113(4), 1106-1112

557 Shantha, N. C., \& Decker, E. A. (1994). Rapid, sensitive, iron-based spectrophotometric methods for 558 determination of peroxide values of food lipids. Journal of AOAC International, 77(2), 421-424.

559 Stephansen, K. B., Chronakis, I. S., \& Jessen, F. (2014). Bioactive electrospun fish sarcoplasmic 560 proteins as an oral delivery system. Colloids and Surfaces B: Biointerfaces, 122(1), 158-165.

561 Tao, J., \& Shivkumar, S. (2007). Molecular weight dependent structural regimes during the 562 electrospinning of PVA. Materials Letters, 61(11-12), 2325-2328. 
563 Torres-Giner, S., Martinez-Abad, A., Ocio, M. J., \& Lagaron, J. M. (2010). Stabilization of a 564 nutraceutical omega-3 fatty acid by encapsulation in ultrathin electrosprayed zein prolamine. Journal 565 of Food Science, 75(6), N69-N79.

566 Uauy R, \& Valenzuela A, (2000). Marine Oils: the health benefits of n-3 fatty acids. Nutrition, 16(7567 8), 680-684.

568 Wan, Y., Bankston Jr, J. D., Bechtel, P. J., \& Sathivel, S. (2011). Microencapsulation of menhaden 569 fish oil containing soluble rice bran fiber using spray drying technology. Journal of Food Science, $57076(4)$, E348-E356.

571 Ward, O.P., \& Singh, A. (2005). Omega-3/6 fatty acids: alternative sources of production. Process 572 Biochemistry, 40(12), 3627-3652.

573 Weiss, J., Kanjanapongkul, K., Wongsasulak, S., \& Yoovidhya, T. (2012). Electrospun fibers: 574 Fabrication, functionalities and potential food industry applications. In Q. Huang (Ed.), 575 Nanotechnology in the food, beverage and nutraceutical industries (pp 362-397). Woodhead 576 Publishing Ltd: Cambridge.

577 Xu, X., Chen, X., Ma, P., Wang, X., \& Jing, X. (2008). The release behavior of doxorubicin 578 hydrochloride from medicated fibers prepared by emulsion-electrospinning. European Journal of 579 Pharmaceutics and Biopharmaceutics, 70(1), 165-170.

580 Yarin, A. L. (2011). Coaxial electrospinning and emulsion electrospinning of core-shell fibers. 581 Polymers for Advanced Technologies, 22(3), 310-317.

582 Zhu, X., Gao, Q., Xu, D., \& Shi, X. (2009). Effect of interaction between hydroxyl group and high 583 valence metal ion impurity on the electrospinnability of polyvinyl alcohols. Journal of Applied 584 Polymer Science, 113(1), 143-149. 
585

586

587

588

589

590

591

592

593

594

595

596

597

598

599

600

601

\section{FIGURE AND TABLE CAPTIONS}

- Figure 1. Properties of electrospinning solutions: a) droplet size distribution after 1 day of production (10.5\% PVA, w/w), b) droplet size distribution during storage (10.5\% PVA, w/w; WPI), c) droplet size distribution during storage (10.5\% PVA, w/w; FPH) and d) viscosity.

- Figure 2. SEM micrographs and fiber diameter distribution of electrospun mats obtained from 10.5\% (w/w) PVA-emulsion blends stabilized with WPI and containing different fish oil load:

a) $1.5 \%(\mathrm{w} / \mathrm{w})$ oil, b) $2.25 \%(\mathrm{w} / \mathrm{w})$ oil and c) $3 \%(\mathrm{w} / \mathrm{w})$ oil.

- Figure 3. SEM micrographs and fiber and bead diameter distribution of electrospun mats obtained from PVA-emulsion blends stabilized with FPH: a) 10.5\% (w/w) PVA-1.5\% (w/w) oil, b) 9\% (w/w) PVA-2\% (w/w) oil and c) 7.5\% (w/w) PVA-2.5\% (w/w) oil.

- Figure 4. Lipid distribution within the fibers: a) confocal image, b) variation of droplet size distribution.

- Figure 5. Increase of the concentration of secondary oxidation products during storage at $40{ }^{\circ} \mathrm{C}$ in a) unprotected fish oil, b) emulsified fish oil, and c) electrospun fibers.

- Table 1. Composition (\%,w/w) of PVA-emulsion blends for electrospinning.

- Table 2: Peroxide value during storage at $40{ }^{\circ} \mathrm{C}$ for unprotected and emulsified fish oil, fibers and PVA-emulsion blends. 
Table 1. Composition (\%,w/w) of PVA-emulsion blends for electrospinning

\begin{tabular}{|c|c|c|c|c|}
\hline \multirow[b]{2}{*}{ Emulsifier } & \multirow{2}{*}{$\begin{array}{l}\text { Fish oil load in emulsion, } \\
\qquad \%(w / w)\end{array}$} & \multicolumn{3}{|c|}{ Solutions for electrospinning } \\
\hline & & Exp.\# & $\begin{array}{c}\text { Concentration of PVA, } \\
\%(w / w)\end{array}$ & $\begin{array}{c}\text { Concentration of fish oil, } \\
\%(w / w)\end{array}$ \\
\hline \multirow{9}{*}{ WPI } & \multirow{3}{*}{5.0} & 1 & 10.5 & 1.50 \\
\hline & & 2 & 9.0 & 2.00 \\
\hline & & 3 & 7.5 & 2.50 \\
\hline & \multirow{3}{*}{7.5} & 4 & 10.5 & 2.25 \\
\hline & & 5 & 9.0 & 3.00 \\
\hline & & 6 & 7.5 & 3.75 \\
\hline & \multirow{3}{*}{10.0} & 7 & 10.5 & 3.00 \\
\hline & & 8 & 9.0 & 4.00 \\
\hline & & 9 & 7.5 & 5.00 \\
\hline \multirow{9}{*}{$\mathrm{FPH}$} & \multirow{3}{*}{5.0} & 10 & 10.5 & 1.50 \\
\hline & & 11 & 9.0 & 2.00 \\
\hline & & 12 & 7.5 & 2.50 \\
\hline & \multirow{3}{*}{7.5} & 13 & 10.5 & 2.25 \\
\hline & & 14 & 9.0 & 3.00 \\
\hline & & 15 & 7.5 & 3.75 \\
\hline & \multirow{3}{*}{10.0} & 16 & 10.5 & 3.00 \\
\hline & & 17 & 9.0 & 4.00 \\
\hline & & 18 & 7.5 & 5.00 \\
\hline
\end{tabular}


Table 2: Peroxide value during storage at $40{ }^{\circ} \mathrm{C}$ for unprotected and emulsified fish oil, fibers and PVA-emulsion blends

\begin{tabular}{|c|c|c|c|c|c|c|c|c|}
\hline \multicolumn{9}{|c|}{$\mathbf{P V}$, meq $\mathrm{O}_{2} / \mathrm{kg}$ oil } \\
\hline & Oil & Emulsion & Fibers & ${ }^{1}$ Fibers, $\mathbf{N}_{2}$ & $\begin{array}{l}{ }^{2} \text { PVA }(13.5 \%) \\
\text { fibers, } \mathrm{N}_{2}\end{array}$ & $\begin{array}{c}{ }^{3} \text { PVA (10.5\%)-EDTA } \\
\text { emulsion blend }\end{array}$ & $\begin{array}{l}{ }^{4} \text { PVA }(10.5 \%)+ \\
\text { EDTA fibers, } \mathrm{N}_{2}\end{array}$ & $\begin{array}{l}{ }^{5} \text { PVA (10.5\%)- } \\
\text { emulsion blend }\end{array}$ \\
\hline Day 0 & $0.4 \pm 0.1^{a}$ & $0.2 \pm 0.1^{a}$ & $54.6 \pm 9.3^{b, c}$ & $42.5 \pm 3.2^{b}$ & $64.5 \pm 1.1^{\mathrm{c}}$ & $14.7 \pm 2.6^{\mathrm{a}}$ & $43.9 \pm 7.8^{b}$ & $16.1 \pm 2.2^{\mathrm{a}}$ \\
\hline Day 4 & $11.9 \pm 0.2^{a, b}$ & $2.2 \pm 0.1^{a}$ & $393.7 \pm 24.7^{c}$ & $304.4 \pm 11.0^{d}$ & - & $42.1 \pm 1.9^{a, b}$ & - & $48.4 \pm 0.8^{b}$ \\
\hline Day 9 & $18.3 \pm 0.1^{\mathrm{a}}$ & $14.9 \pm 0.2^{\mathrm{a}}$ & $175.1 \pm 8.9^{b}$ & $221.0 \pm 18.2^{c}$ & - & $50.5 \pm 1.1^{\mathrm{a}}$ & - & $144.4 \pm 9.7^{b}$ \\
\hline Day 14 & $14.7 \pm 0.6^{\mathrm{a}}$ & $17.7 \pm 2.6^{\mathrm{a}}$ & $94.9 \pm 20.2^{a, b}$ & $141.7 \pm 51.0^{b, c}$ & - & $61.2 \pm 1.1^{a, b}$ & - & $208.6 \pm 0.1^{c}$ \\
\hline
\end{tabular}

${ }^{1}$ Fibers produced from $10.5 \%(\mathrm{w} / \mathrm{w})$ PVA-emulsion blend under nitrogen atmosphere.

${ }^{2}$ Fibers produced from $13.5 \%(\mathrm{w} / \mathrm{w})$ PVA-emulsion blend under nitrogen atmosphere.

${ }^{3} 10.5 \%(\mathrm{w} / \mathrm{w})$ PVA-emulsion blend containing $100 \mathrm{ppm}$ of EDTA in the parent $5 \%(\mathrm{w} / \mathrm{w})$ fish oil-in-water emulsion stabilized with WPI.

${ }^{4}$ Fibers produced from the PVA-emulsion blend described in ${ }^{3}$ under nitrogen atmosphere.

5 10.5\% (w/w) PVA-emulsion blend produced with PVA donated by Kuraray Europe GmbH.

Values within a row with different superscript letters indicate significant differences $(\mathrm{p}<0.05)$ 
(A)

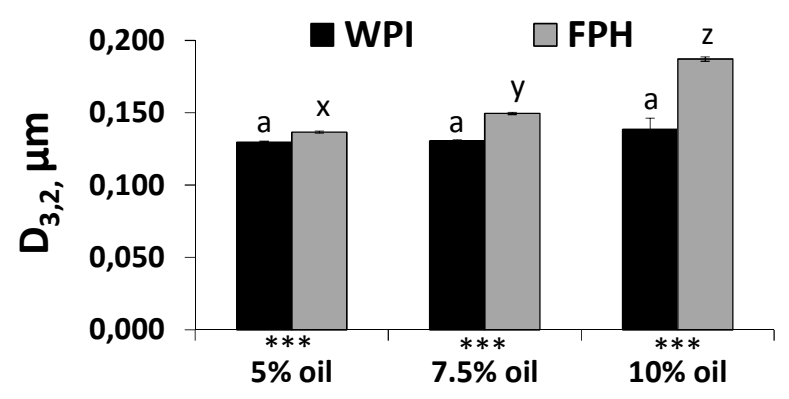

(B)

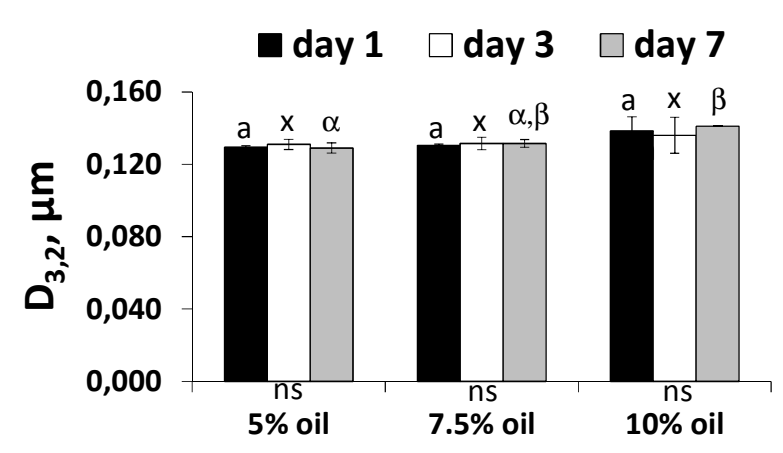

(C)

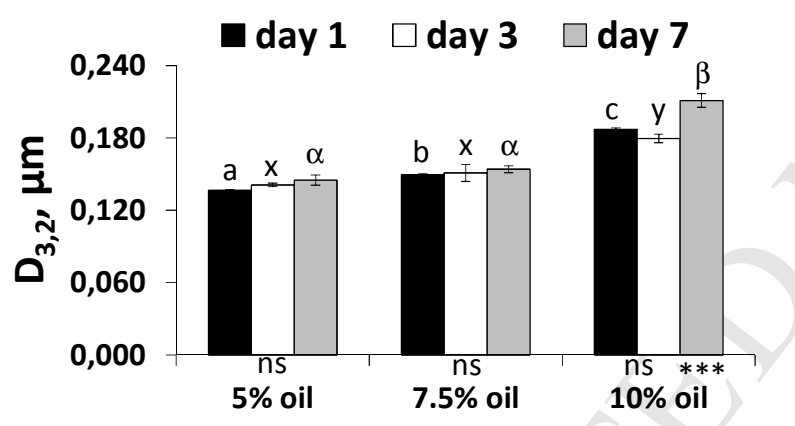

(D)

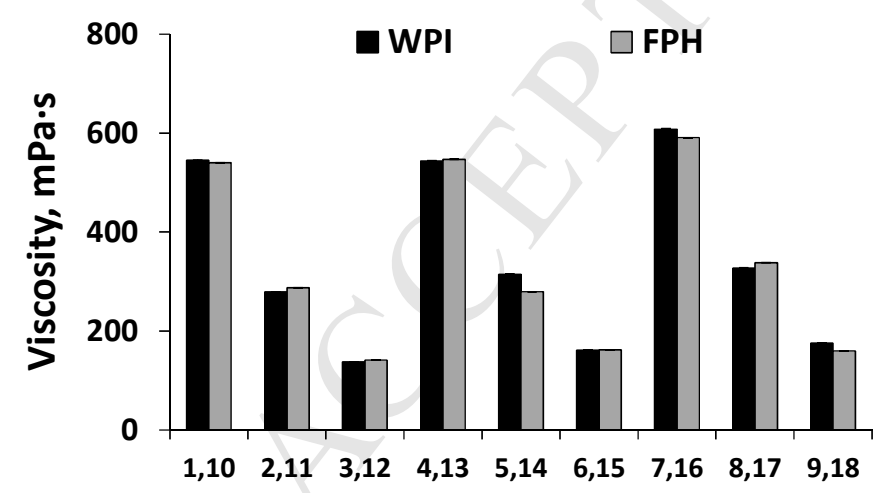

Figure 1. Properties of electrospinning solutions: a) droplet size distribution after 1 day of production (10.5\% PVA, w/w), b) droplet size distribution during storage (10.5\% PVA, w/w; WPI), c) droplet size distribution during storage (10.5\% PVA, w/w; $\mathrm{FPH}$ ) and d) viscosity.

In Fig. 1a, stars indicate significant differences between WPI and FPH samples for the individual oil concentrations. Letter "a" indicates not significant differences among WPI samples, whereas letters " $x$ ", " $y$ " and " $z$ " indicate significant differences among FPH samples $(p<0.05)$.

In Fig. 1b-c, stars indicate significant differences among samples at day 1, 3 and 7 for the individual oil concentrations (ns: not significantly different). Letters " $a, b$ and $c$ ", " $x$ and $y$ " and Greek letters " $\alpha$ and $\beta$ " indicate significant differences among samples at day 1, 3 and 7, respectively $(\mathrm{p}<0.05)$.

In Fig. 1d, numbers correspond to experiment numbers. 
(A)
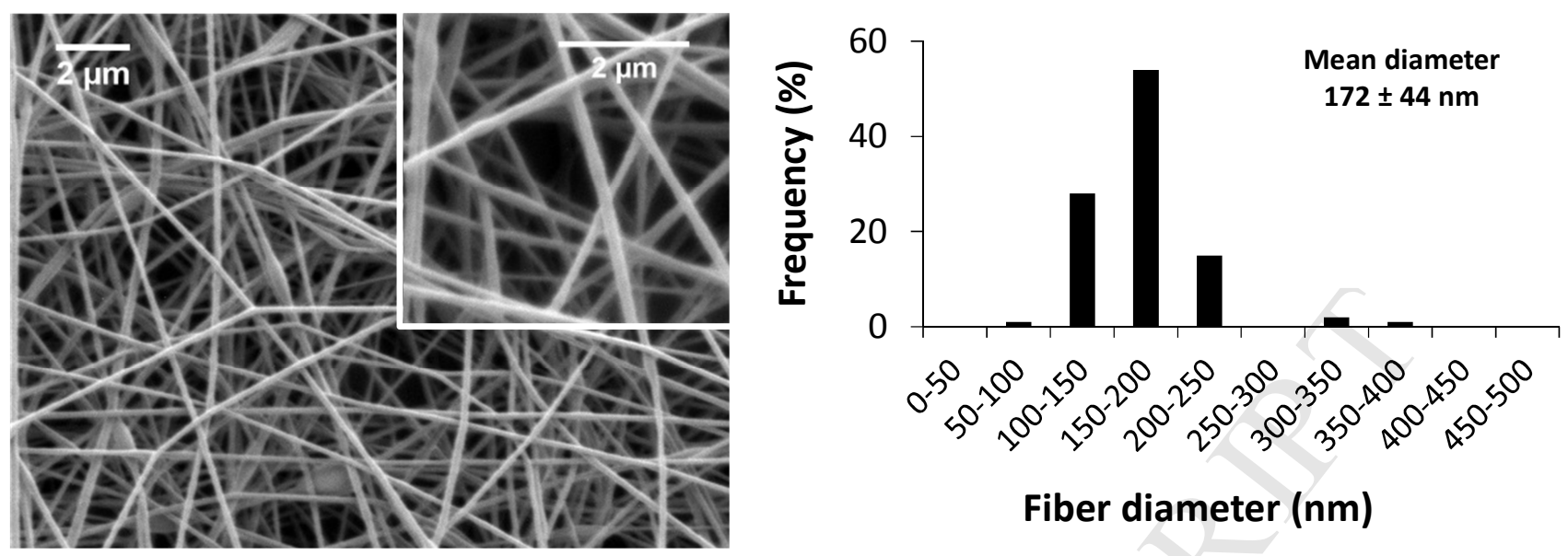

Fiber diameter (nm)

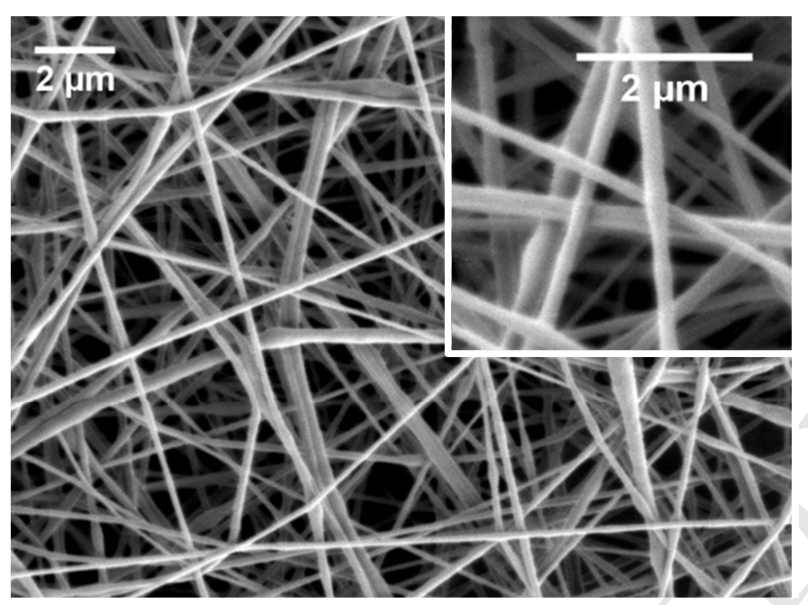

(B)

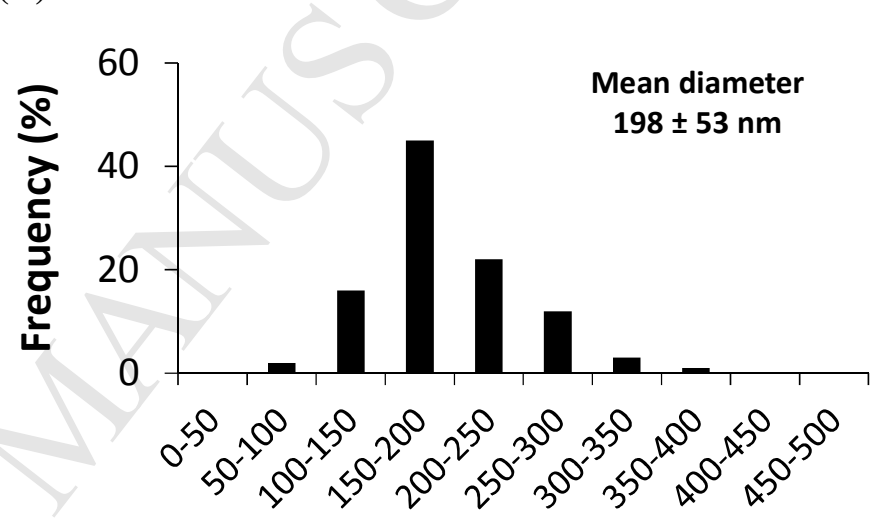

Fiber diameter (nm)

(C)
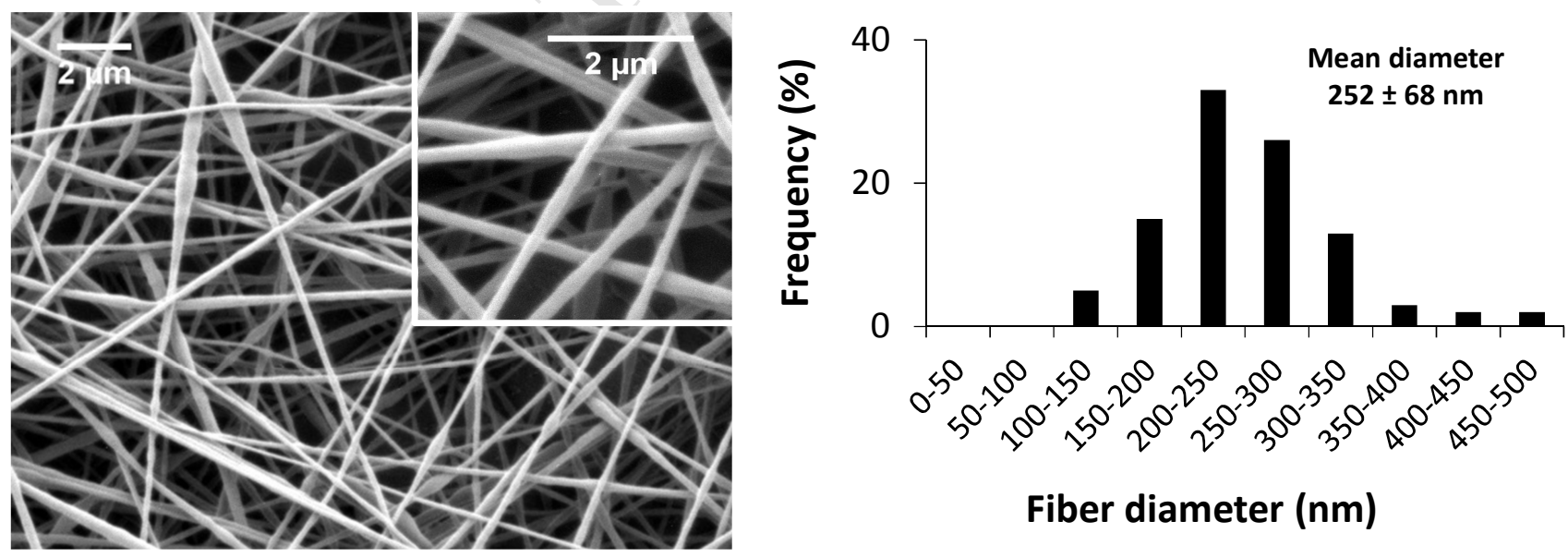

Fiber diameter (nm)

Figure 2. SEM micrographs and fiber diameter distribution of electrospun mats obtained from $10.5 \%(\mathrm{w} / \mathrm{w})$ PVA-emulsion blends stabilized with WPI and containing different fish oil load: a) $1.5 \%$ (w/w) oil, b) $2.25 \%(\mathrm{w} / \mathrm{w})$ oil and c) $3 \%(\mathrm{w} / \mathrm{w})$ oil. 
(A)
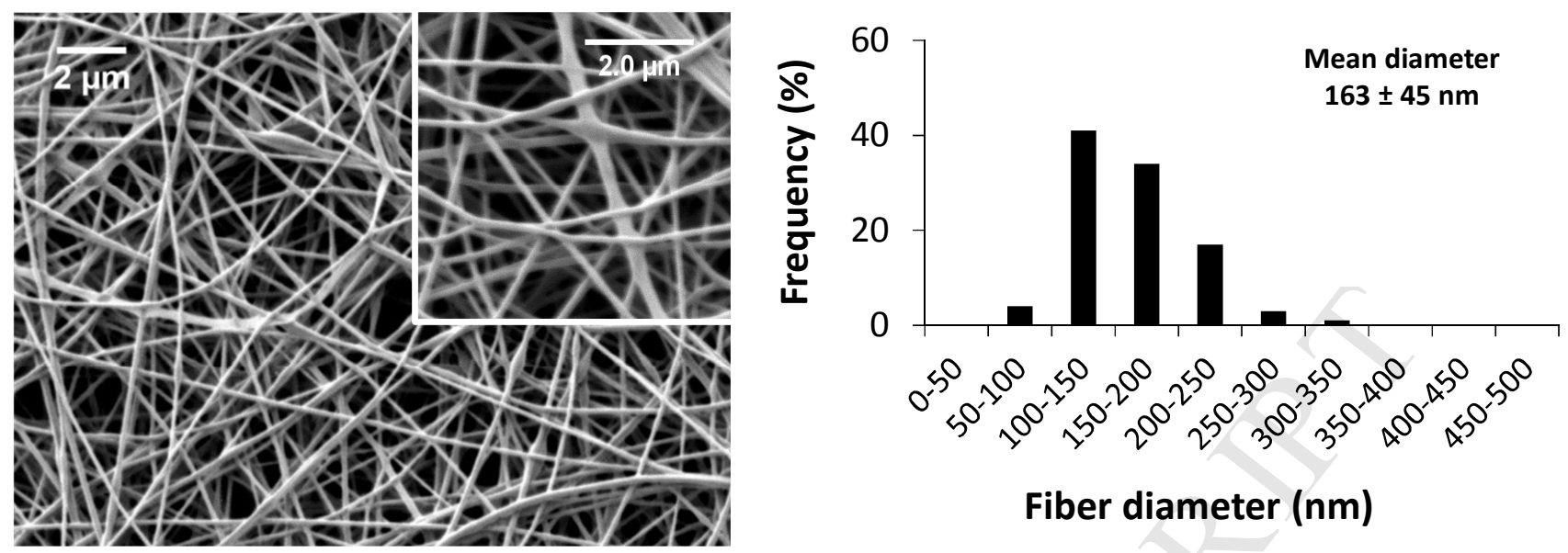

Fiber diameter $(\mathrm{nm})$

(B)
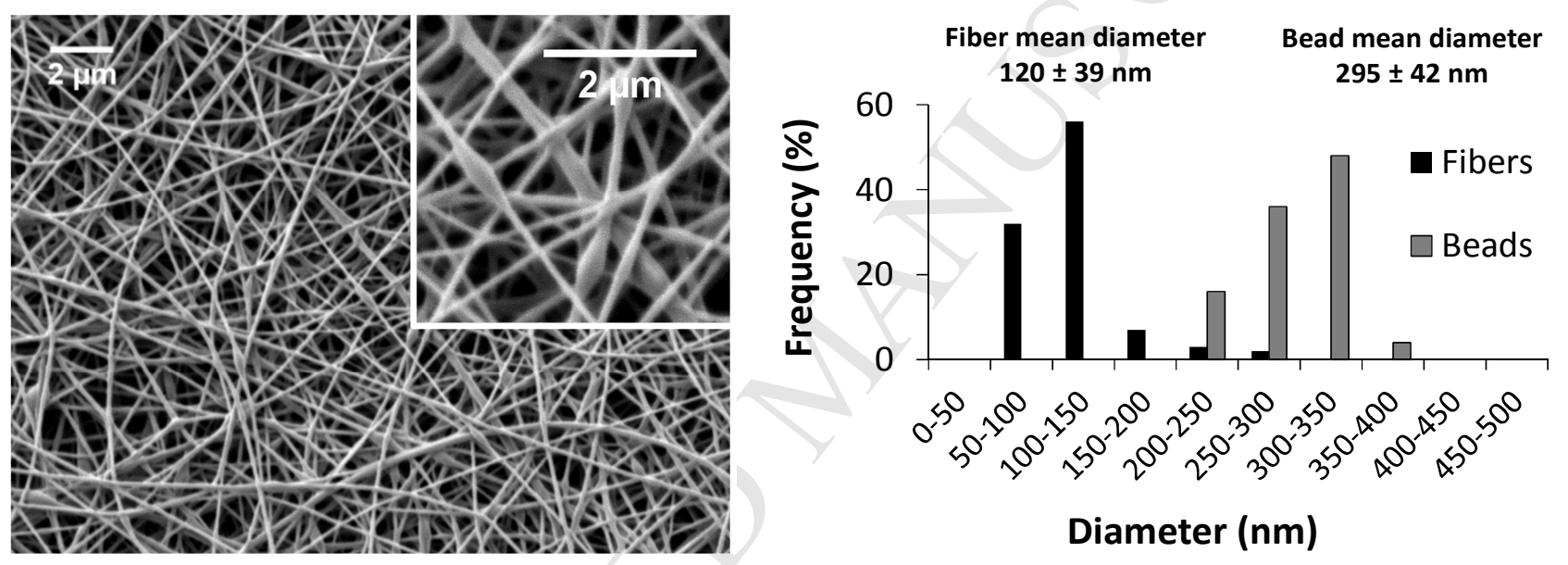

(C)
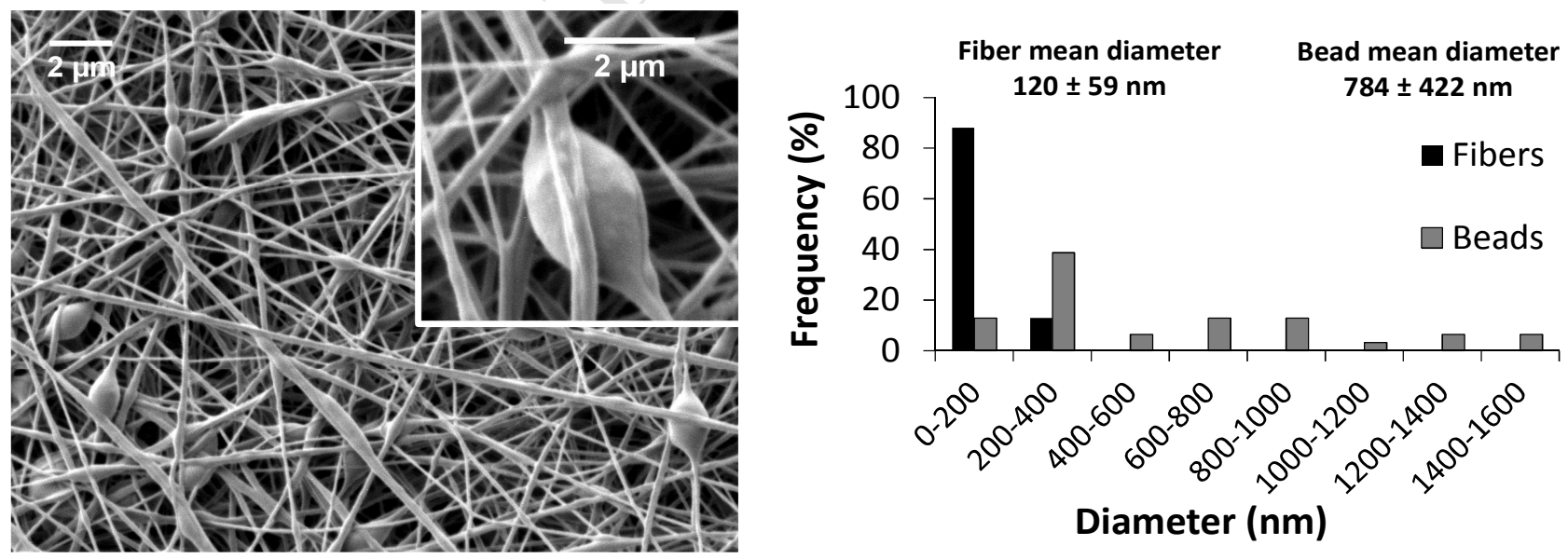

Figure 3. SEM micrographs and fiber and bead diameter distribution of electrospun mats obtained from PVA-emulsion blends stabilized with FPH: a) 10.5\% (w/w) PVA-1.5\% (w/w) oil, b) 9\% (w/w) PVA-2\% (w/w) oil and c) $7.5 \%(w / w)$ PVA-2.5\% (w/w) oil. 
(A)

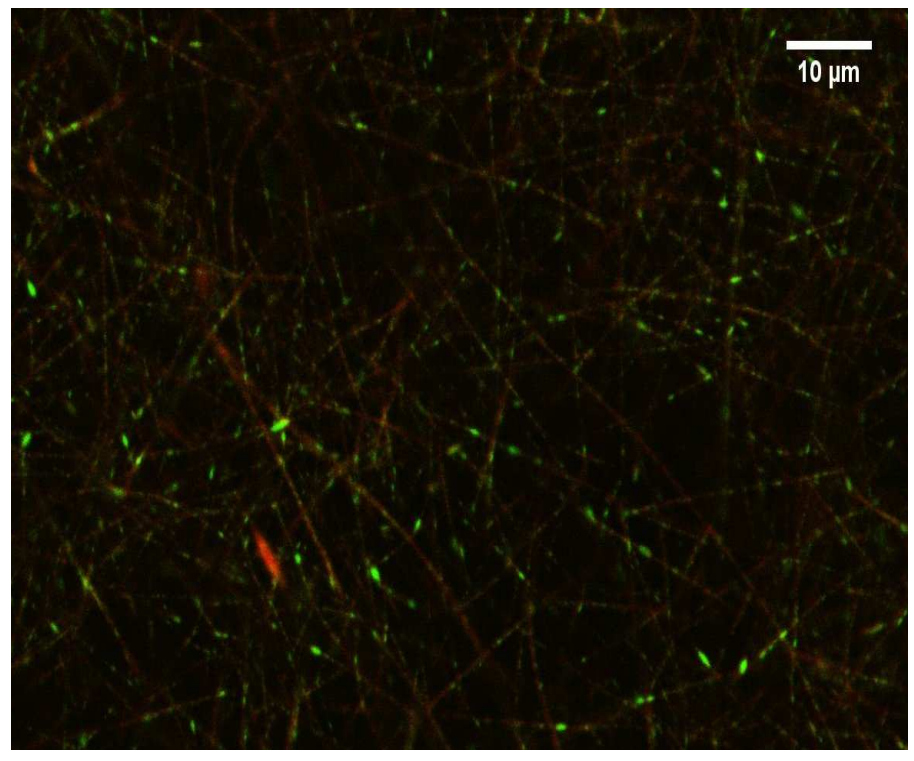

(B)

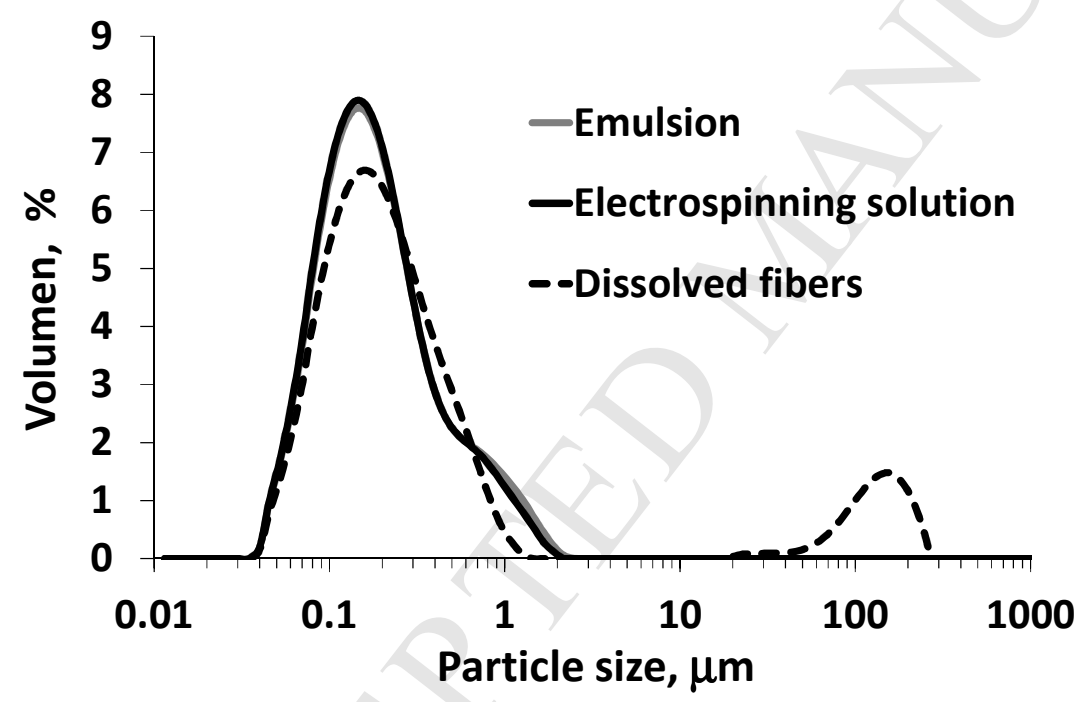

Figure 4. Lipid distribution within the fibers: a) confocal image, b) variation of droplet size distribution. 
(A)

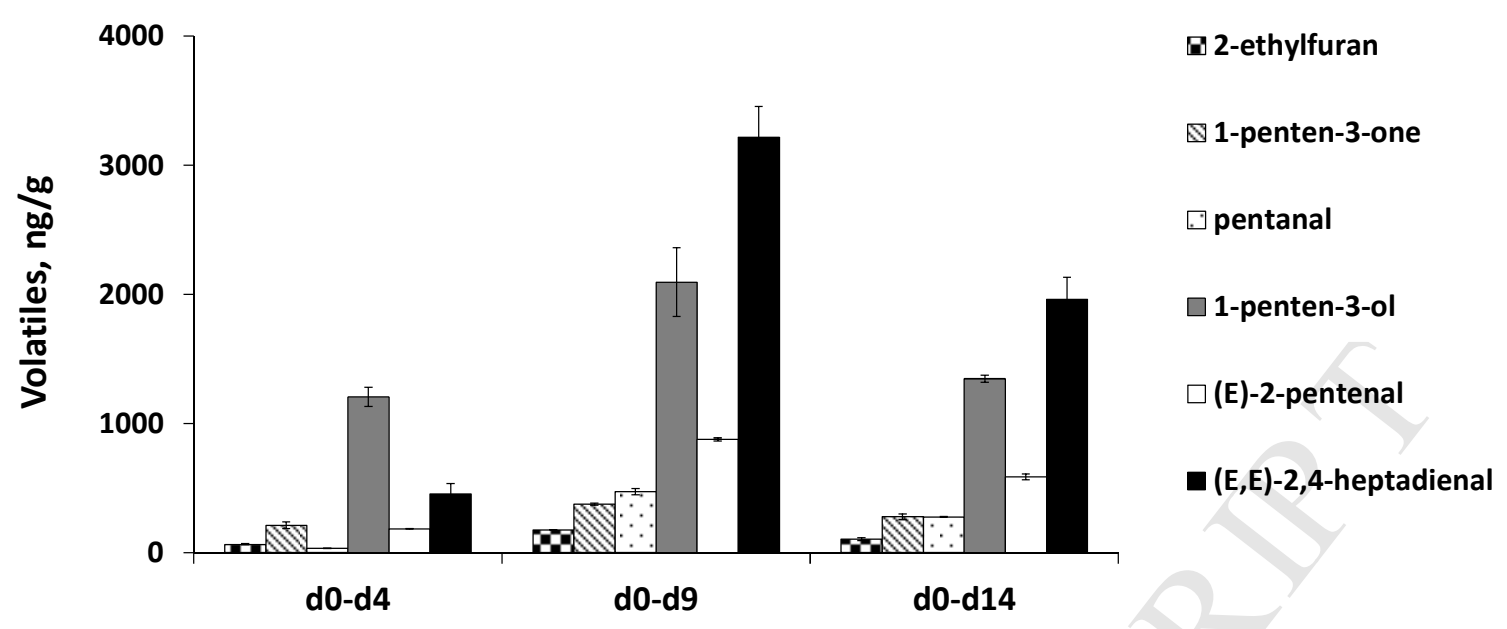

(B)

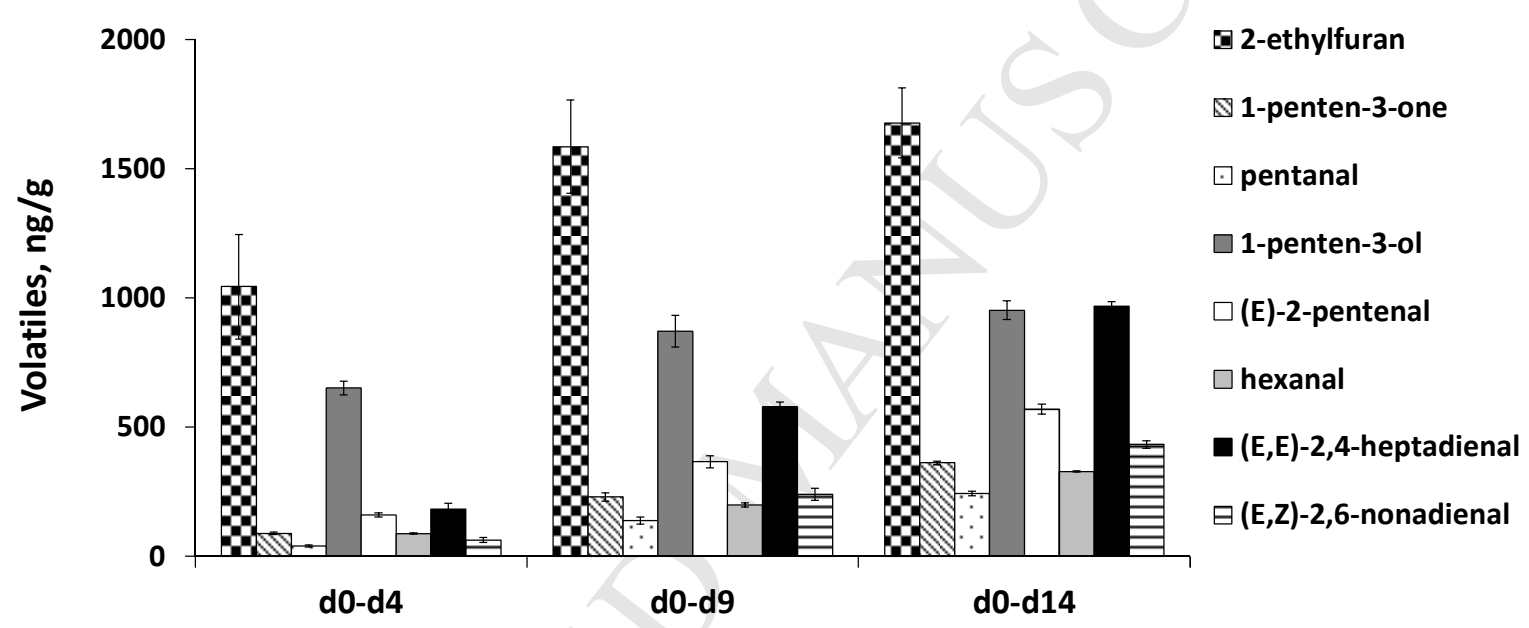

(C)

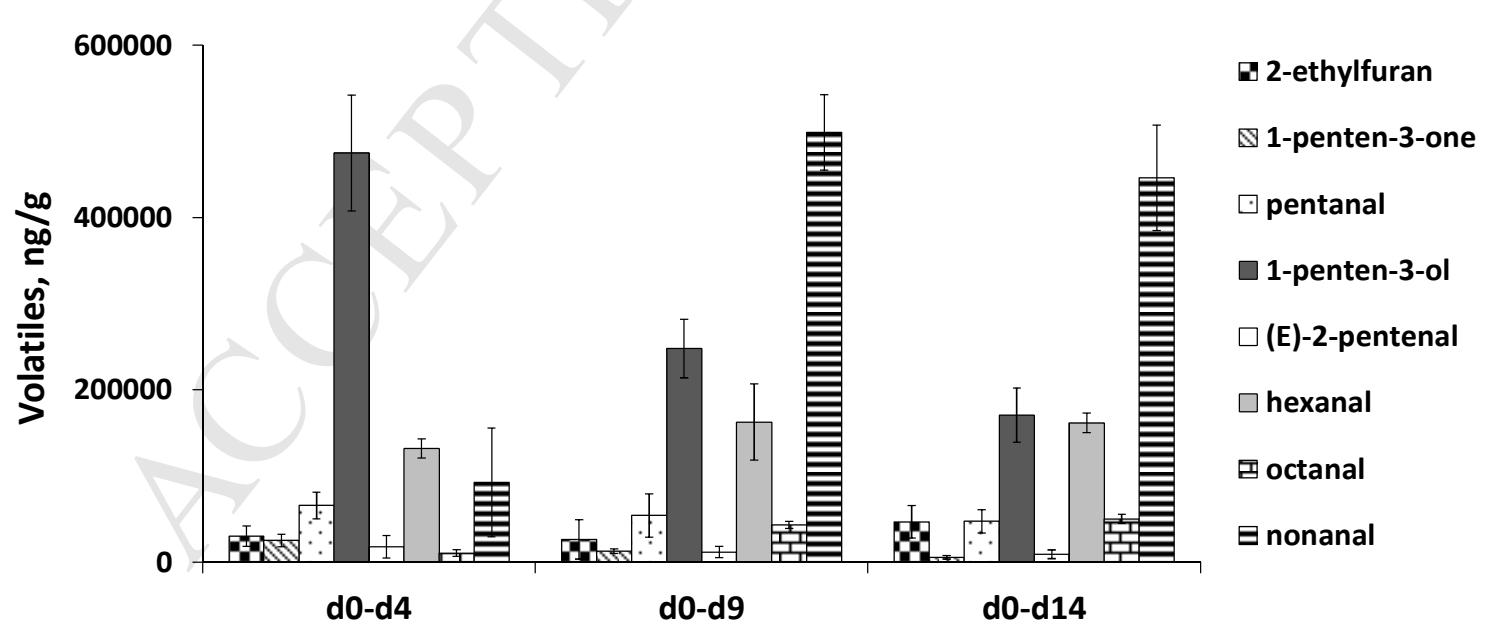

Figure 5. Increase of the concentration of secondary oxidation products during storage at $40{ }^{\circ} \mathrm{C}$ in a) unprotected fish oil, b) emulsified fish oil, c) electrospun fibers. 


\section{Highlights}

- Fibers loaded with fish oil were successfully produced by emulsion electrospinning

- Decreasing PVA concentration ( $<10.5 \mathrm{wt} \%)$ led to spindle-like and spherical beads

- Increasing oil load has a minor influence on fiber morphology

- Most of fish oil was randomly distributed inside the fibers as small droplets

- Electrospun nanofibers presented a poor oxidatively stability 